\title{
How Not to Discover a New Reagent. The Evolution and Chemistry of Woollins' Reagent.
}

\author{
J Derek Woollins \\ EaStCHEM School of Chemistry, University of St Andrews, St Andrews, Fife UK KY16 9ST \\ Fax: 44 (0)1334 463384 \\ E-mail:jdw3@st-and.ac.uk. \\ Received: The date will be inserted once the manuscript is accepted. \\ This review is dedicated to the 'coworkers' ( - in reality the workers) who performed the studies described here.
}

\begin{abstract}
The pathways in research can be complex. This review provides a personal account of the winding scientific and funding road which led to Woollins' Reagent. The synthesis and demonstrative reactions of Woollins' Reagent are summarized.
\end{abstract}

Keywords: Synthesis, heterocycle, phosphorus, selenium, group 16.

Whilst preparing this review I was acutely aware that the guidelines explicitly request that authors incorporate the background to their research and personal context and I have taken this seriously; I have provided a story, warts and all. . This article will provide a review of the development of Woollins' Reagent - the zig zag story not the polished lecture! Inevitably there is some sense of autobiography and I set the scene with rather unrelated work which, I hope, illustrates the 'philosophy' and the joy of research in my labs. I must admit that I have also grasped the opportunity to review some simple S-N and Se-N chemistry - I am sure this area deserves more recognition and study than it currently receives.

I have been lucky enough to work with a range of very talented people over the past 35 years and certainly in the early days of my research career eccentricity often went hand in hand with brilliance. Sadly, in my view, there has been a leveling down in terms of behavior and style of academic staff and we, as a community, are poorer for it.

It is conventional to mention a burning desire to study chemistry that was instilled by a Damascas moment in which one had a blinding flash of inspiration igniting a lifelong desire to improve things for humanity through chemistry. I had none of this whilst at school and indeed slid through with the minimum of effort. As part of my general laziness and contrariness (and against lots of good advice) I chose to study chemistry, physics and religion as my three specialist subjects in sixth form. The consequence was that when I came to apply to university I didn't have enough maths to do physics or good enough English qualifications to study divinity so was left with chemistry as my only possible option. I started my university life at the University of East Anglia, UEA, (or as it was known back in 1973 for a variety of reasons, the University of Easy Access). I went to UEA for my BSc since I liked the prospect of watching Norwich City in the old English first division and my school grades were really pretty marginal - indeed when I told my school chemistry teacher (an old school character Mr Gregory who was never without his sports coat, leather patches and moustache) that I was going to University to study chemistry he responded ominously 'Woollins, you won't last two weeks'

It turned out that UEA had a really rather good degree program taught with great enthusiasm by luminaries such as Alan Katrizky and Sandy McKillop amongst others and they did inspire and enthuse me greatly. At the end of my BSc I was offered a PhD place with Andrew Thomson and Roger Grinter to work on S-N systems . Neither Andrew or Roger knew anything much about the area but they had noticed the reports on the remarkable properties of $(\mathrm{SN})_{\mathrm{x}}$ and convinced Johnson Matthey to part-fund a project. Andrew has an intellect which still leaves me awestruck, whilst Roger has real depth and knowledge in theory coupled with an accent like a Dorset pig farmer. Two supervisors is a great boon - especially when they both go on sabbaticals during your $\mathrm{PhD}$ - I had a great time and largely pleased myself with the direction of the work with occasional nudges from one or other of my supervisors. Between them Roger and Andrew sparked an inquisitive nature coupled with the need to have long term goals whilst also training me in methodology and time management. After my PhD I was fortunate to undertake postdoctoral work in three quite disparate areas, [1] in asymmetric homogeneous catalysis with Bill Cullen at UBC, Vancouver [2] in platinum anti-cancer chemistry with Rosenberg at MSU, East Lansing and [3] in metallaborane chemistry with Norman Greenwood at Leeds. Norman Greenwood encouraged me to apply for a 'New Blood' lectureship and I was lucky enough to be offered a post at Imperial College by Geoffrey Wilkinson.

I started at IC in Oct 1984. IC was a very competitive environment but had a great 'can do' philosophy. Apart from Wilkinson, inorganic chemistry had some great talents including Denis Evans (originator of the Evans balance and the Evans NMR method) and William Griffith (a brilliant osmium chemist),whilst organic chemistry included young lecturers such as Steve Ley and William Motherwell My research career started in earnest at IC and despite having been 
appointed to a bioinorganic post I won my first research grant to work on $\mathrm{M}-\mathrm{S}-\mathrm{N}$ chemistry.

Our early work focused on trying to bring rational approaches to the synthesis of M-S-N systems. Although the chemistry of SN anions is now fairly well understood very few of these anions are available as 'off the shelf ' salts. In the 1950's BeckeGoehring 1 showed that reaction of $\mathrm{S}_{4} \mathrm{~N}_{4}$ with $\mathrm{Ni}(\mathrm{CO})_{4}$ gives a solid of formula $\mathrm{Ni}(\mathrm{NS})_{4}$ which when refluxed in methanol leads to $\mathrm{Ni}\left(\mathrm{S}_{2} \mathrm{~N}_{2} \mathrm{H}\right)_{2}{ }^{2}$ Later, the reaction of simple metal halides with $\mathrm{S}_{4} \mathrm{~N}_{4}$ was used to prepare $\mathrm{Co}, \mathrm{Ni}, \mathrm{Pd}$ and $\mathrm{Pt}$ complexes of the $\left[\mathrm{S}_{2} \mathrm{~N}_{2} \mathrm{H}\right]^{-}$and $\left[\mathrm{S}_{3} \mathrm{~N}\right]^{-}$anions (eqn 1). ${ }^{3-5}$

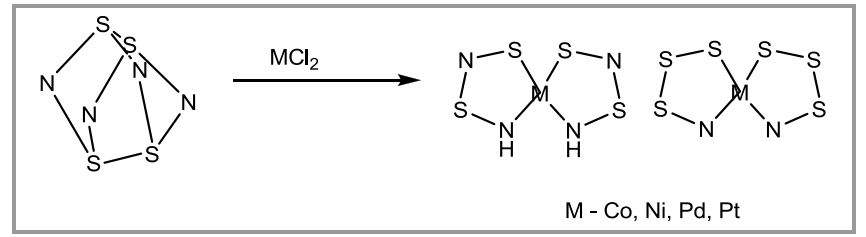

Equation 1

The published reactions were poor yield and hard to generalize. With the hope of developing interesting polymeric and/or stacking $\mathrm{Pt}-\mathrm{S}-\mathrm{N}$ systems we set about developing the area using two strategies, firstly developing the chemistry of $\mathrm{S}_{4} \mathrm{~N}_{4}$ and secondly looking for reagents that could effect simple ligand transfer chemistry. The reaction chemistry of $\mathrm{S}_{4} \mathrm{~N}_{4}$ is an elegant demonstration of the difficulties and complexity of main group chemistry. Its simplest reaction is decomposition to the elements, a thermodynamically favourable reaction which can be achieved with modest shock or heat. Notwithstanding this inherent difficulty $\mathrm{S}_{4} \mathrm{~N}_{4}$ is almost certainly the most studied S-N molecule. It was first synthesized in 1835 and has undergone steady investigation for many years. In the early 70's interest in S-N chemistry received a boost when the unusual 1-D electrical and superconducting properties of $(\mathrm{SN})_{\mathrm{x}}$ were uncovered. ${ }^{8}$ Sulfur-nitrogen chemistry remains a rather unfashionable area which given the unpredictable nature of reactions in this area is a great pity. There are some good reviews in the area which illustrate the beauty of this chemistry. ${ }^{9,10}$ In my early years at IC whilst my group worked on $\mathrm{M}-\mathrm{S}-\mathrm{N}$ and $\mathrm{M}-\mathrm{Se}-\mathrm{N}$ chemistry the organic chemist, Charles Rees ( Derek Barton's successor at IC) uncovered a range of S-N aromatic C-S-N heterocycles first by reactions of $\mathrm{S}_{4} \mathrm{~N}_{4}$ and later using more systematic methods. 11,12 Charles' group were pretty hopeless at the synthesis of the purely inorganic starting materials but always seemed (unlike us) to have beautiful mechanisms; there was a healthy combination of complementarity and rivalry between us during this time.

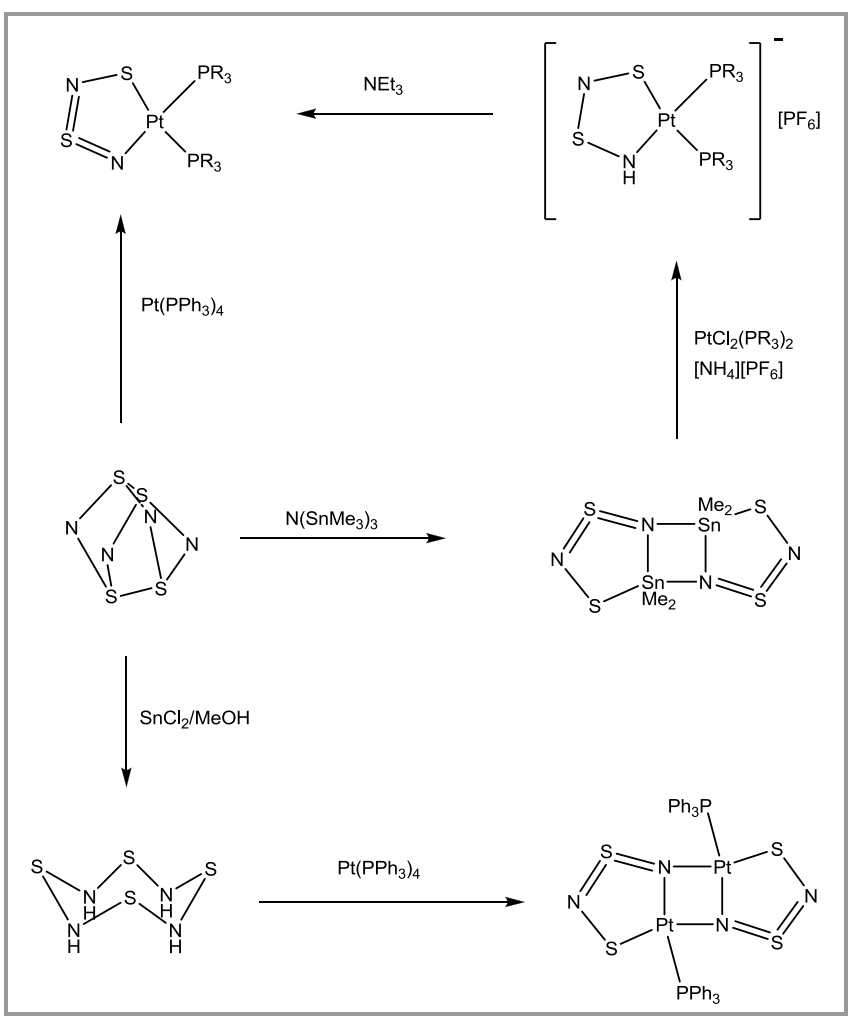

Scheme 1 Examples of Metalla-sulfur-Nitrogen Complexes ${ }^{13-15}$.

Some early examples of routes to M-S-N complexes developed by my first PhD student, Paul Kelly, are shown in Scheme 1. Of particular interest are the $\mathrm{Pt}\left(\mathrm{PR}_{3}\right)_{2}\left(\mathrm{~S}_{2} \mathrm{~N}_{2} \mathrm{H}\right] \mathrm{X}$ systems which form stacked arrangements. ${ }^{16}$ Paul Kelly also later extended this work by making M-Se-N complexes using $\mathrm{Se}_{4} \mathrm{~N}_{4}$ as starting material. ${ }^{17}$ This is very sensitive material; indeed the first time we prepared it (from a reaction in liquid ammonia) whilst washing the red solid with a solution of $\mathrm{KCN}$ the nitrogen was let into the flask fairly briskly - the resulting turbulence caused an explosion which destroyed the flask embedding pieces red selenium into the white shirt Paul was wearing from a distance this looked like major bleeding. Bravery was not lacking in the group during that era and Paul Kelly also carried out what remains as the only published reaction of (extraordinarily explosive) $\mathrm{S}_{5} \mathrm{~N}_{6}$ to give a complex of the $\left[\mathrm{S}_{2} \mathrm{~N}_{3}\right]^{-}$ligand. ${ }^{18}$ Scheme 2 illustrates the reaction of $\mathrm{S}_{4} \mathrm{~N}_{4}$ and $\mathrm{S}_{5} \mathrm{~N}_{6}$ with $\left[\mathrm{PPh}_{4}\right]_{2}\left[\mathrm{Pd}_{2} \mathrm{Cl}_{6}\right]$. A mixture of compounds is formed, one containing the bridging, neutral $\mathrm{S}_{2} \mathrm{~N}_{2}$ ring which is formally a $6 \pi$ aromatic ring whilst the second product contains the $\left[\mathrm{S}_{3} \mathrm{~N}_{2}\right]^{2-}$ dianion. ${ }^{19}$. Reaction of $\mathrm{S}_{4} \mathrm{~N}_{4}$ with gaseous chlorine results in ring cleavage to give $(\mathrm{NSCl})_{3}$ whereas Roesky showed ${ }^{20}$ very elegantly that treatment with liquid chlorine is milder and results in disubstitution to give $\mathrm{S}_{4} \mathrm{~N}_{4} \mathrm{Cl}_{2}$. This latter compound eliminates $\mathrm{MeSiCl}$ when treated with $\left(\mathrm{Me}_{3} \mathrm{SiN}\right)_{2} \mathrm{~S}$ and gives the air sensitive and very explosive $\mathrm{S}_{5} \mathrm{~N}_{6}$. The reaction of $\mathrm{S}_{5} \mathrm{~N}_{6}$ with $\left[\mathrm{PPh}_{4}\right]_{2}\left[\mathrm{Pd}_{2} \mathrm{Cl}_{6}\right]$ gives $\left[\mathrm{PPh}_{4}\right]\left[\mathrm{PdCl}_{2}\left(\mathrm{~S}_{2} \mathrm{~N}_{3}\right)\right]$ which contains the only known example of an $\left[\mathrm{S}_{2} \mathrm{~N}_{3}\right]^{-}$ ligand. The complexity of this type of chemistry is 
further illustrated by the reaction of $\mathrm{S}_{4} \mathrm{~N}_{4}$ with $\left[\mathrm{PPh}_{4}\right]_{2}\left[\mathrm{PtCl}_{4}\right]$ which gives $\left[\mathrm{PPh}_{4}\right]\left[\mathrm{PtCl}_{3}\left(\mathrm{~S}_{4} \mathrm{~N}_{4}\right)\right]$ containing $\mathrm{Pt}(\mathrm{IV})$ and the $\left[\mathrm{S}_{4} \mathrm{~N}_{4}\right]^{2-}$ dianion. Our contribution to M-S-N chemistry has been reviewed. ${ }^{15}$ In subsequent years we developed M-Se-N chemistry but the main reason to discuss our M-S-N chemistry is to set the scene for our work on P-S and P-Se chemistry. Largely as a consequence of our published work on M-S-N chemistry and the dearth of other $p$ block chemists in the UK, I was approached by a division of EXXON and invited to work on P-S chemistry.

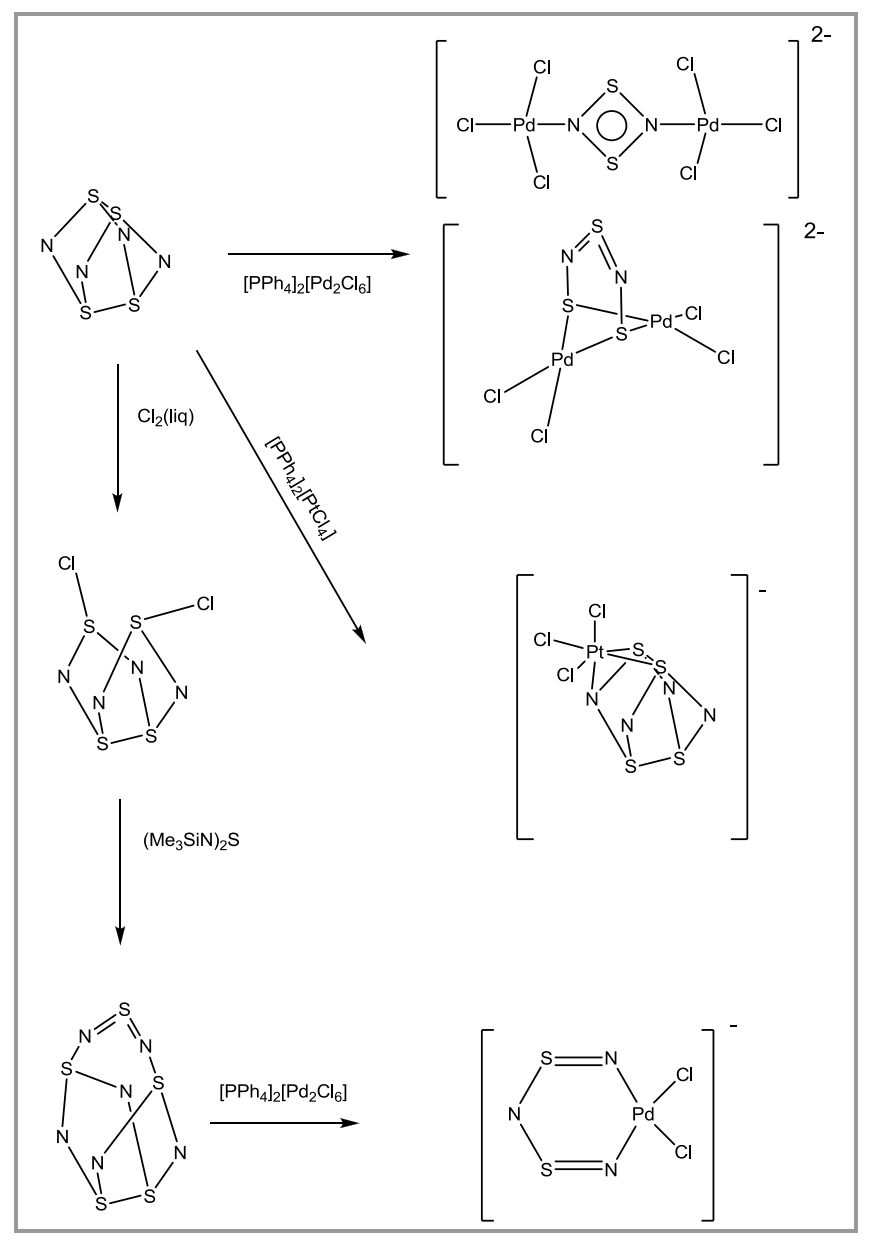

Scheme 2 Examples of M-S-N complexes prepared by us, illustrating the difference in reactivity of $\mathrm{S}_{4} \mathrm{~N}_{4}$ and $\mathrm{S}_{5} \mathrm{~N}_{6}$

A major use of P-S chemistry is the synthesis of zinc dialkyldithiophosphates which are added to engine oil as anti-oxidants. Although these compounds are made on quite large scale (multi-tonne) there can be problems with the synthetic route. The simplified synthesis is shown in scheme 3. Reaction of the cheap and readily available $\mathrm{P}_{4} \mathrm{~S}_{10}$ with alcohol gives the dialkyldithiophosphoric acid (DDP) which is neutralized to give the zinc complex (ZDDP). DDP with small $\mathrm{R}$ groups such as methyl are thermally unstable and thus both to improve the additive properties and avoid handling dangerous systems larger $\mathrm{R}$ groups and complexation with zinc are used to produce the commercial material which is added to engine oils. In fact depending on the conditions it is also possible to prepare so called basic ZDDP of the formula $\mathrm{Zn}_{4} \mathrm{O}(\mathrm{DDP})_{6}$.

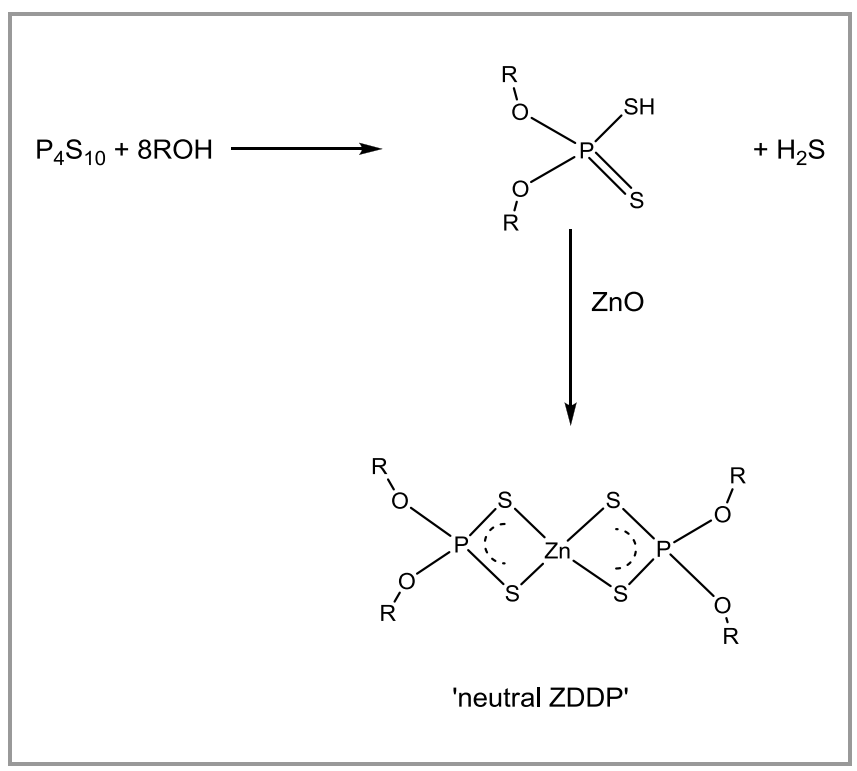

Scheme 3 Commercial synthesis of zinc dialkyldithiophosphates.

Although this chemistry has been in use since the 1950s there are still complexities and it was only fairly recently that we showed the structure of basic ZDDP is analogous to beryllium acetate with a tetrahedron of zinc atoms surrounding a central $\mathrm{O}^{2-}$ dianion and every edge of the zinc tetrahedron being chelated by a DDP ligand. ${ }^{22}$

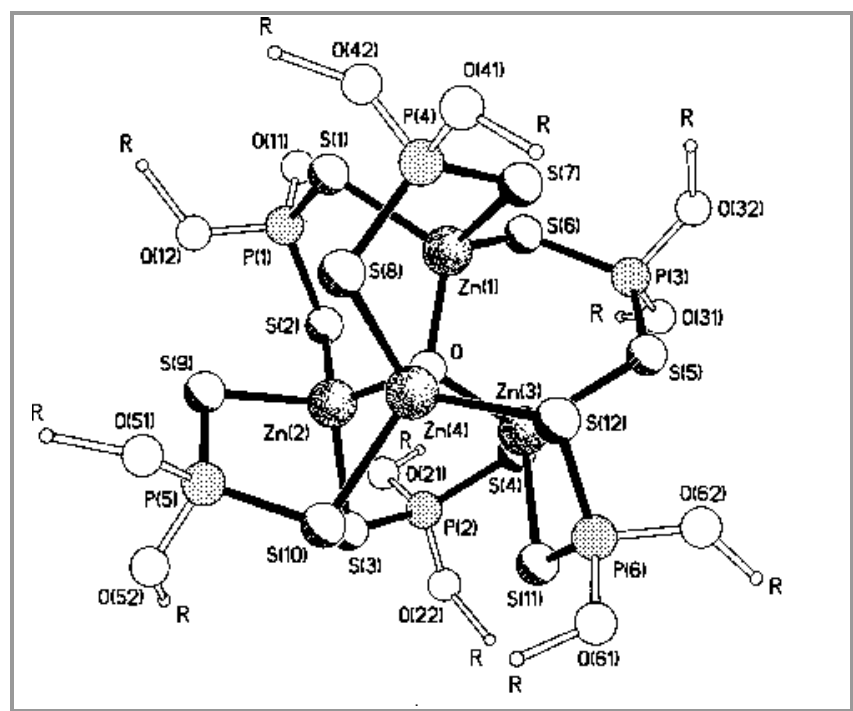

Figure 1 The crystal structure of basic $\mathrm{Zn}_{4} \mathrm{O}\left[\mathrm{S}_{2} \mathrm{P}\left(\mathrm{OBu}^{\mathrm{i}}\right)_{2}\right]_{6}$; only the first carbon atom of each $\mathrm{Bu}^{\mathbf{i}}$ is illustrated (denoted $\mathrm{R}$ ) for clarity. ${ }^{22}$

The synthesis of DDP and ZDDP can be problematical with rather large variability in reaction rates. Careful examination of samples of $\mathrm{P}_{4} \mathrm{~S}_{10}$ showed that this material is often contaminated with traces of $\mathrm{P}_{4} \mathrm{~S}_{9}$ and $\mathrm{S}_{8}$ (almost certainly from incomplete reaction of $\mathrm{P}_{4}$ 
and $\mathrm{S}_{8}$ during the manufacturing process) . This process (Scheme 3 ) is thus not ideal and also suffers from the environmental problem that it generates $\mathrm{H}_{2} \mathrm{~S}$.

As part of this work with EXXON Paul Wood developed elegant routes to zinc dialkylmonothiophosphates (ZDMP, Equation 2). ${ }^{23}$

$\mathrm{ZnO}+2 \mathrm{HP}(\mathrm{O})(\mathrm{O} i \mathrm{Pr})_{2}+1 / 4 \mathrm{~S}_{8}$

$$
\rightarrow \quad \mathrm{Zn}\left[\mathrm{O}(\mathrm{S}) \mathrm{P}(\mathrm{O} i \mathrm{Pr})_{2}\right]+\mathrm{H}_{2} \mathrm{O}
$$

Equation 2

These O,S ligands demonstrate classical hard soft ligand behaviour in complexation reactions ${ }^{24}$ thus whilst reaction of ZDDP with $\mathrm{Pt}\left(\mathrm{PMe}_{2} \mathrm{Ph}\right)_{2} \mathrm{Cl}_{2}$ proceeds with elimination of $\mathrm{ZnCl}_{2}$ to give $\left[\mathrm{Pt}\left(\mathrm{PMe}_{2} \mathrm{Ph}\right)_{2}\left(\mathrm{~S}_{2} \mathrm{P}(\mathrm{OR})_{2}\right]^{-}\right.$reaction of $\mathrm{ZDMP}$ results in insertion of the $\mathrm{S}-\mathrm{P}-\mathrm{O}$ backbone into the $\mathrm{Pt}-\mathrm{Cl}$ bond to give $\left(\mathrm{PMe}_{2} \mathrm{Ph}\right)_{2} \mathrm{Pt}\left(\mathrm{SP}(\mathrm{OR})_{2} \mathrm{O}\right)_{2} \mathrm{ZnCl}_{2}$ (Figure 2).

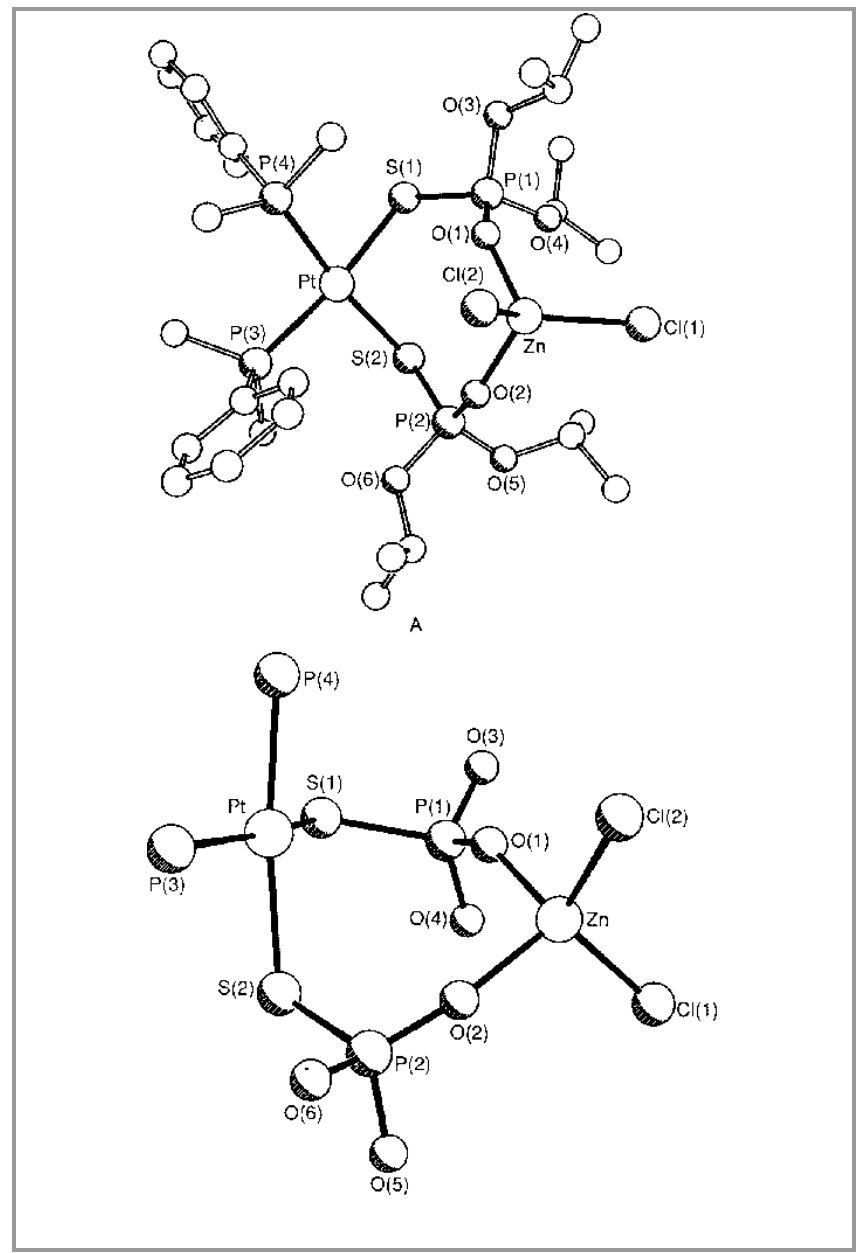

Figure 2 The $\mathrm{X}$-Ray structure of $\left(\mathrm{PMe}{ }_{2} \mathrm{Ph}\right)_{2} \mathrm{Pt}\left(\mathrm{SP}(\mathrm{OR})_{2} \mathrm{O}\right)_{2} \mathrm{ZnCl}_{2}$, upper complete molecule, lower core illustrating $\mathrm{O}$ coordination to $\mathrm{Zn}$ and $\mathrm{S}$ coordination to Pt.

Interestingly, changing the phosphine on the platinum influences the reaction as well so reaction of ZDMP with $\mathrm{Pt}\left(\mathrm{PMe}_{3}\right)_{2} \mathrm{Cl}_{2}$ gives a trimetallic complex
$\left[\left(\mathrm{PMe}_{3}\right) \mathrm{Pt}\left(\mathrm{SP}(\mathrm{OR})_{2} \mathrm{O}\right)_{2}(\mu-\mathrm{Cl}) \mathrm{Zn}\left(\mathrm{SP}(\mathrm{OR})_{2} \mathrm{O}\right)_{2}(\mu-\right.$ $\left.\mathrm{Cl}) \mathrm{Pt}) \mathrm{PMe}_{3}\right){ }^{25}$

This period in my research group was very lively, apart from Paul Kelly (now Reader at Loughborough) working on $\mathrm{M}-\mathrm{S} / \mathrm{Se}-\mathrm{N}$ chemistry, Ivan Parkin (now Professor and Head of Dept at UCL, London) Paul Wood (now Lecturer at Cambridge University) were competing to deliver exciting new work. Parkin developed some very direct routes to M-S- N and MSe-N complexes using reactions in liquid ammonia, ${ }^{17 b, 26}$ whilst Kelly continued to show his skill and imagination by using an imaginative route to isolate the $\left[\mathrm{S}_{3} \mathrm{~N}_{3}\right]^{-}$anion. ${ }^{27}$ Chivers published elegant work on S-N anions and our engagement in this area leant on his work whilst occasionally causing uncomfortable tensions and these could have been quite destructive especially since the US and UK editors of Polyhedron independently commissioned reviews on M-S-N chemistry from us both. ${ }^{13,14}$ Although Chivers pioneered S-N anion chemistry Paul Kelly prepared this anion by a neat reduction using cobaltocene $^{27}$

$4\left[\mathrm{CoCp}_{2}\right]+3 \mathrm{~S}_{4} \mathrm{~N}_{4} \rightarrow 4\left[\mathrm{CoCp}_{2}\right]\left[\mathrm{S}_{3} \mathrm{~N}_{3}\right]$

Equation 3

The resulting material forms infinite stacks of alternating cations and anions with weak $\mathrm{C}-\mathrm{H}^{\prime \prime} \mathrm{N}$ hydrogen bonds (Figure 3) with the solid material being dark red but solutions being yellow indicating strong charge transfer interactions.

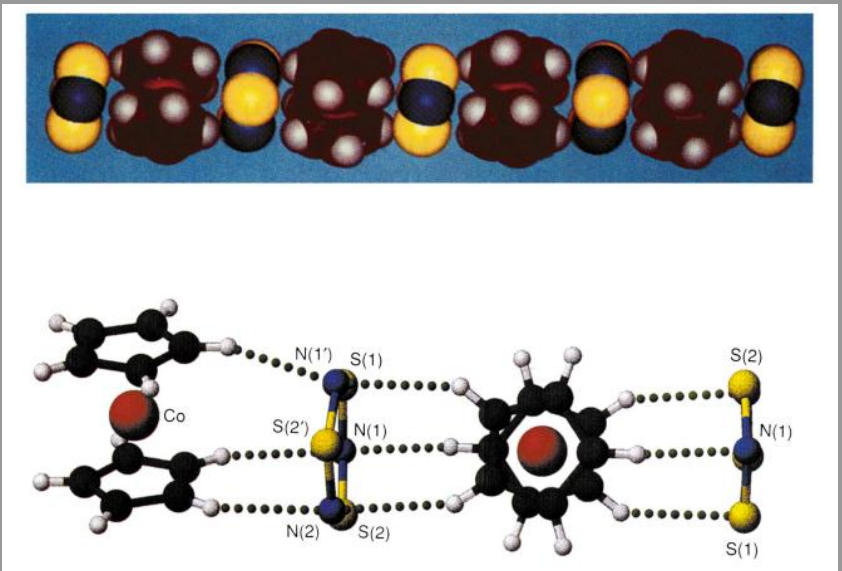

Figure 3 The $X$-Ray structure of $\left[\mathrm{CoCp}_{2}\right]\left[\mathrm{S}_{3} \mathrm{~N}_{3}\right]$. Upper is the space filling representation, lower is detail of the packing showing the cation-anion interactions. ${ }^{27}$

Against the backdrop of strong competition from others in my group, Paul Wood rose to the challenge in two different ways which have both had lasting impact on the direction of our research. Firstly, as mentioned above we had found that $\mathrm{P}_{4} \mathrm{~S}_{10}$ had variable rates of reaction because of the presence of $\mathrm{P}_{4} \mathrm{~S}_{9}$. During attempts to make pure samples of $\mathrm{P}_{4} \mathrm{~S}_{9}$ Paul Wood serendipitously prepared a peri substituted 
naphthalene system. Reaction of $\mathrm{P}_{4} \mathrm{~S}_{3}$ with $\mathrm{S}_{8}$ in $\alpha$ bromonaphthalene at $240{ }^{\circ} \mathrm{C}$ was reported to give $\mathrm{P}_{4} \mathrm{~S}_{9}$ in moderate yield. ${ }^{28}$ However the reaction is very sensitive to the conditions used. We found that in order to maximise the yield of $\mathrm{P}_{4} \mathrm{~S}_{9}$ a slightly lower temperature is preferable. If the temperature is raised to $240{ }^{\circ} \mathrm{C}$, and above, naphthalenedithiadiphosphetanedisulfide $\mathbf{N a p P}_{2} \mathbf{S}_{\mathbf{4}}$ is obtained (Figure 4). ${ }^{29}$

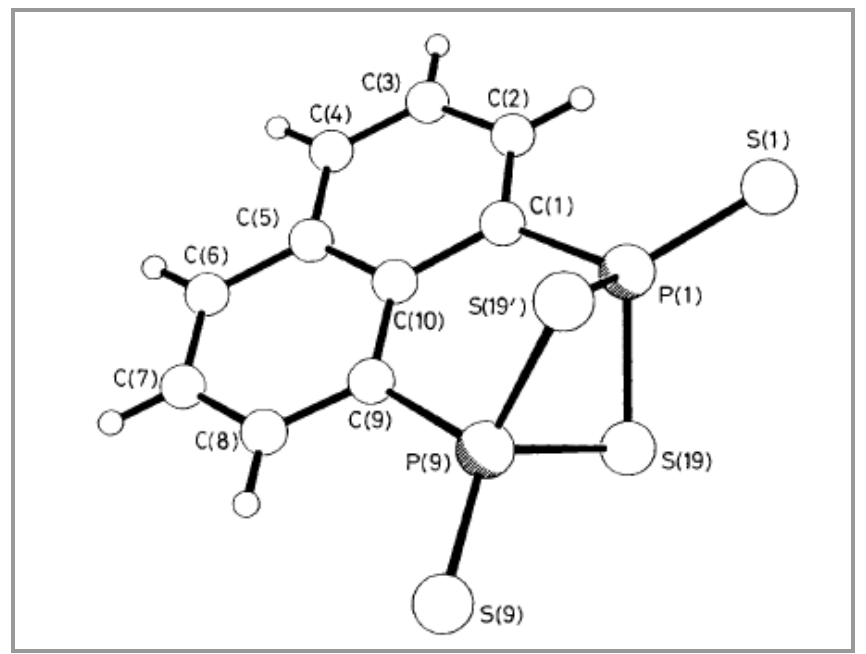

Figure 4 The X-Ray structure of naphthalenedithia diphosphetanedisulfide ${ }^{29}$

The identity of $\mathbf{N a p P}_{2} \mathbf{S}_{4}$ baffled us for a while and we needed X-Ray crystallography to settle this problem. Alexandra Slawin started her long collaboration with me around this time.. This has been very fruitful - she is a genuinely brilliant crystallographer who will tackle any problem even with lousy crystals. To paraphrase the advert 'I liked the crystallographer so much I married her'. $\mathbf{N a p} \mathbf{P}_{2} \mathbf{S}_{\mathbf{4}}$ can be thought of as a cis analogue of Lawesson's Reagent and was our first forage into organic reaction chemistry - we showed it is capable of sulfur transfer reaction. Over the twenty years since we made $\mathbf{N a p P}_{\mathbf{2}} \mathbf{S}_{\mathbf{4}}$, we recognized how hard it is to make 1,8 (peri) substituted naphthalenes and used the peri arrangement to isolate some unusual systems as well as developing insight into weak bonding/repulsive effects using the naphthalene backbone as a molecular scaffolding. This work has been reviewed ${ }^{30}$ but here I mention one or two highlights.

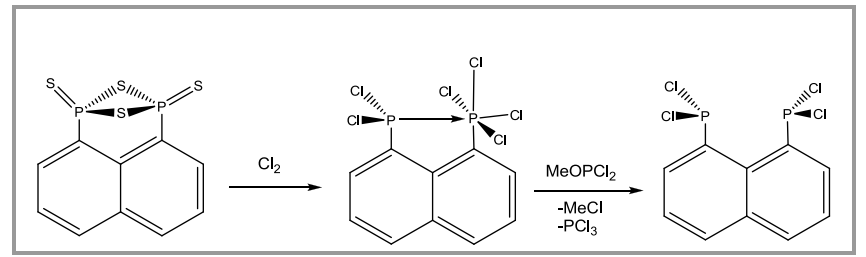

Equation 4

Preparation of $1,8 \mathrm{Nap}\left(\mathrm{PR}_{2}\right)_{2}$ systems is surprisingly difficult with the expected dilithiation giving poor yields but we found that chlorination of $\mathbf{N a p P}_{2} \mathbf{S}_{4}$ gives $\mathrm{Nap}\left(\mathrm{PCl}_{2}\right)\left(\mathrm{PCl}_{4}\right)$ containing a rare intra- molecular $\mathrm{P}(\mathrm{III}) \rightarrow \mathrm{P}(\mathrm{V})$ dative covalent bond. $^{31}$ Removal of the chlorine to give $\mathrm{Nap}\left(\mathrm{PCl}_{2}\right)_{2}$ was surprisingly difficult until we used $(\mathrm{MeO}) \mathrm{PCl}_{2}$ which eliminates $\mathrm{PCl}_{3}$ and $\mathrm{MeCl}$ to give the desired bis phosphine chloride in quantitative yield. ${ }^{32}$ This material represents the ideal synthon for making a wide range of alkyl and aryl substituted naphthalene bis phosphines. Reaction of $\operatorname{Nap}\left(\mathrm{PCl}_{2}\right)_{2}$ with oxygen results in oxidation of one phosphorus centre to give $\mathrm{Nap}\left(\mathrm{POCl}_{2}\right)\left(\mathrm{PCl}_{2}\right)$ and subsequent reaction with chlorine generates $\mathrm{Nap}\left(\mathrm{POCl}_{2}\right)\left(\mathrm{PCl}_{4}\right)$ (equation5) containing two $\mathrm{P}(\mathrm{V})$ centres. ${ }^{33}$ The bridging $\mathrm{P}=\mathrm{O}$ group results in hypercoordination of the $\mathrm{RPCl}_{4}$ centre with a P..O distance of $1.505(2) \AA$.

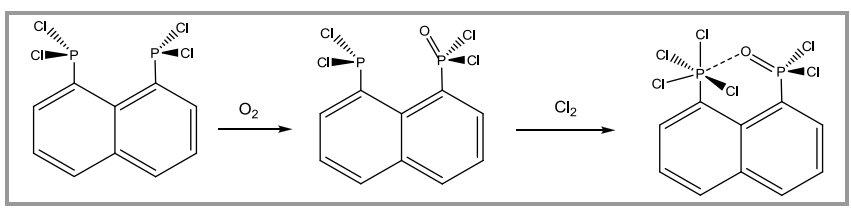

Equation 5

More recent work on phosphorus systems has included using the naphthalene backbone to stabilize unusual cations and dications (scheme 4). ${ }^{34}$

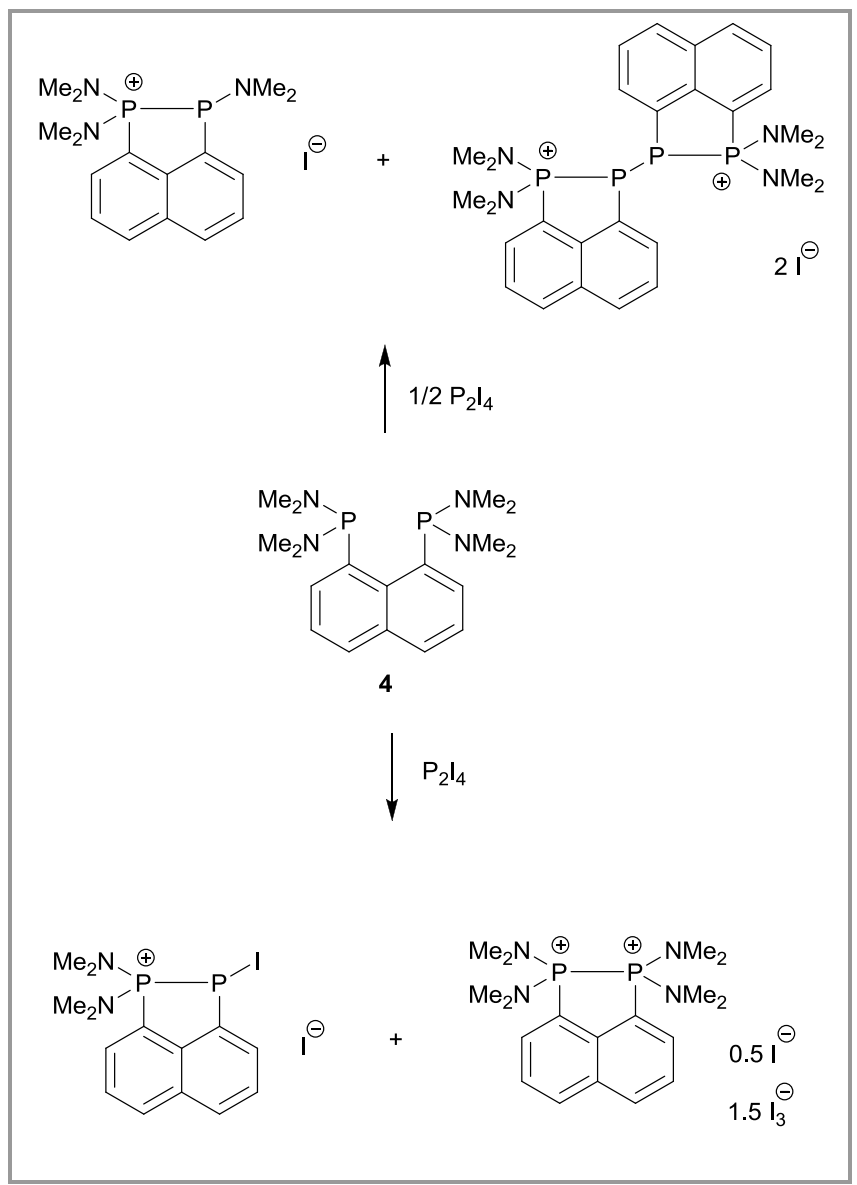

Scheme 4 Reactions of peri substituted phosphine to give cationic and chain species. $^{34}$

This early work by Paul Wood also ultimately led via some convoluted routes to our interest in group 16 
peri substituted systems. We have prepared an extensive range of peri substituted naphthalene systems investigating the repulsive and attractive effects associated with forcing two heavy elements into close proximity (schemes 5,6 ). ${ }^{35}$ Weak attractive forces are apparent, depending on the orientation of the substituents. Reactions of these peri substituted systems with halogens have proved particularly exciting. Thus, A range of diverse compounds $\left\{\mathrm{Nap}[\mathrm{SPh}]_{2} \cdot \mathrm{Br}_{4} \quad(\mathrm{Nap}=\right.$ naphthalene-1,8-diyl); $\mathrm{Nap}[\mathrm{SePh}][\mathrm{EPh}] \cdot \mathrm{Br}_{4}(\mathrm{E}=\mathrm{Se}, \mathrm{S}) ; \mathrm{Nap}[\mathrm{SePh}]_{2} \cdot \mathrm{I}_{2}$; $\mathrm{Nap}[\mathrm{SePh}][\mathrm{EPh}] \cdot 3 / 2 \mathrm{I}_{2}(\mathrm{E}=\mathrm{Se}, \mathrm{S}) ; \mathrm{Nap}[\mathrm{TePh}][\mathrm{G}] \cdot \mathrm{X}_{2}$ $(\mathrm{G}=\mathrm{SePh}, \mathrm{SPh}, \mathrm{Br}, \mathrm{I} ; \mathrm{X}=\mathrm{Br}, \mathrm{I})$; $\left.\left[\mathrm{Nap}\left(\mathrm{PPh}_{2} \mathrm{OH}\right)(\mathrm{SPh})\right]^{+} \mathrm{Br}_{3}^{-}\right\}$formed from perisubstituted naphthalene chalcogen-donors $\left\{\mathrm{Nap}[\mathrm{ER}]\left[\mathrm{E}^{\prime} \mathrm{R}\right] \quad\left(\mathrm{ER} / \mathrm{E}^{\prime} \mathrm{R}=\mathrm{SPh}, \mathrm{SePh}, \mathrm{TePh}\right)\right.$; $\left.\mathrm{Nap}[\mathrm{TePh}][\mathrm{X}](\mathrm{X}=\mathrm{Br}, \mathrm{I}) ; \mathrm{Nap}\left[\mathrm{PPh}_{2}\right][\mathrm{SPh}]\right\}$ and dibromine and diiodine were studied by $\mathrm{X}$-ray crystallography. ${ }^{35 \mathrm{~d}}$

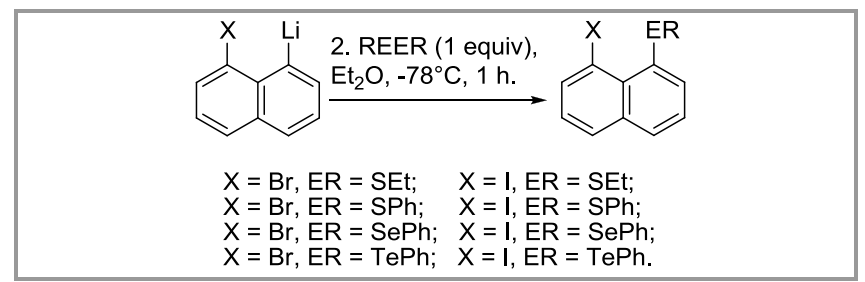

Scheme 5 The preparation of 1-halo-8-(alkylchalcogeno)naphthalenes

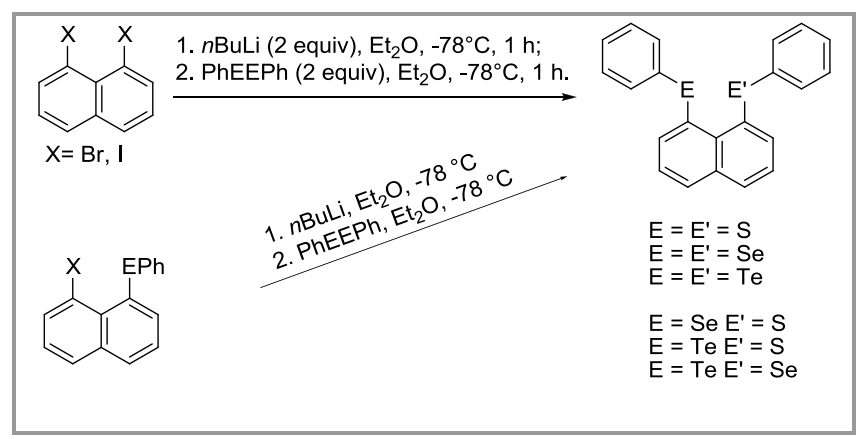

Scheme 6 The preparation of 1,8-dalkylchalcogenonaphthalenes

In general the conformation of the final products obeyed the rule based on charge-transfer ie. 'see-saw' adducts arise when the halogen $(\mathrm{X})$ is more electronegative than the chalcogen (E) and if the converse is true then C.-T. 'spoke' adducts are formed (scheme 7). Upon treatment with dibromine, selenium containing compounds $\left\{\mathrm{Nap}[\mathrm{SePh}]_{2}\right\}$ and $\{\mathrm{Nap}[\mathrm{SePh}][\mathrm{SPh}]\}$ afford unusual tribromide salts of bromoselenyl cations containing a hypervalent $\mathrm{X}$ $\mathrm{E}^{\cdots} \mathrm{E}^{\prime} 3 \mathrm{c}-4 \mathrm{e}$ type interaction. These adducts form complex structures in the solid state eg. short intermolecular contacts exist in the TeX adducts constructing planar $\mathrm{Te}_{2} \mathrm{X}_{2}$ squares (Figure 5)

Peri substitution is hard to direct synthetically and after developing the naphthalene systems we found that acenapthene systems are synthetically much more readily prepared and provide an excellent backbone or molecular scaffolding for studying weak interactions between heavier elements. ${ }^{37}$

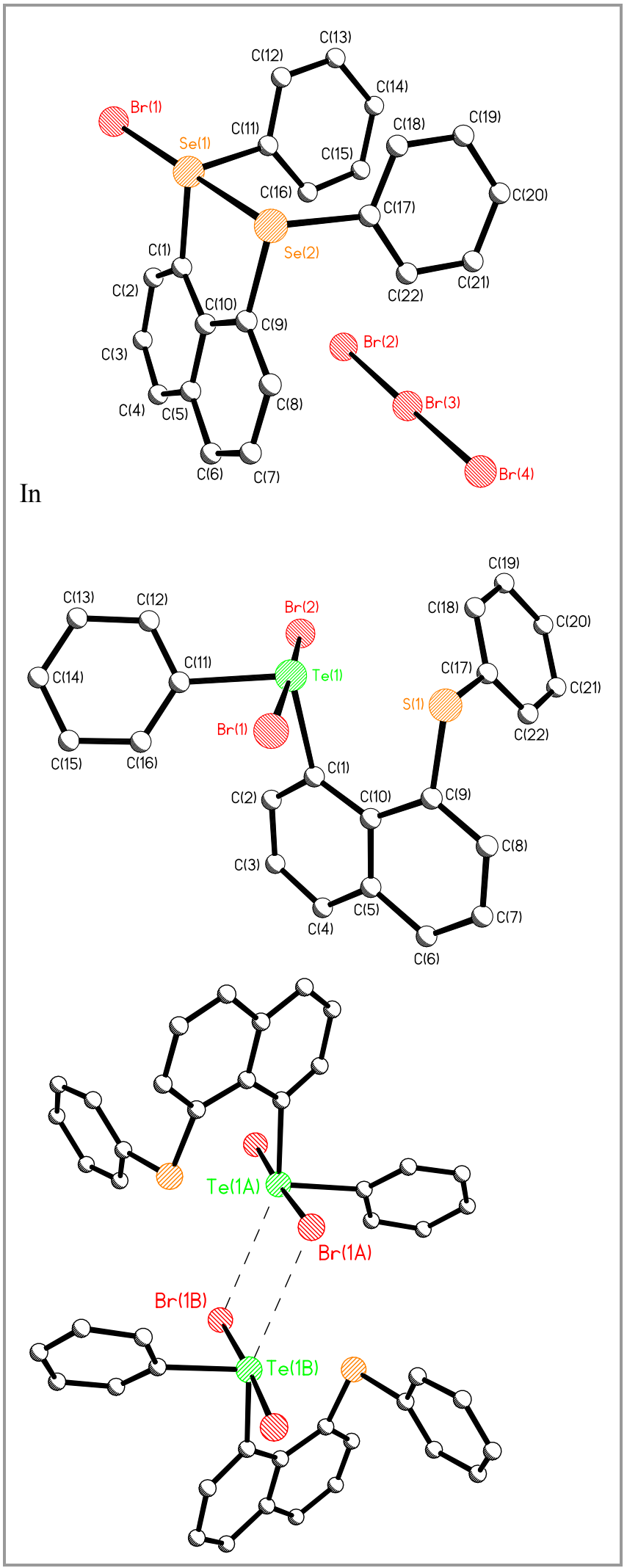

Figure 5 Upper The X-ray structure of a typical ionic C.-T. 'extended spoke' adduct, middle a typical 'see-saw' adduct formed from Nap(EPh)2. And lower intramolecular packing in seesaw adducts. 


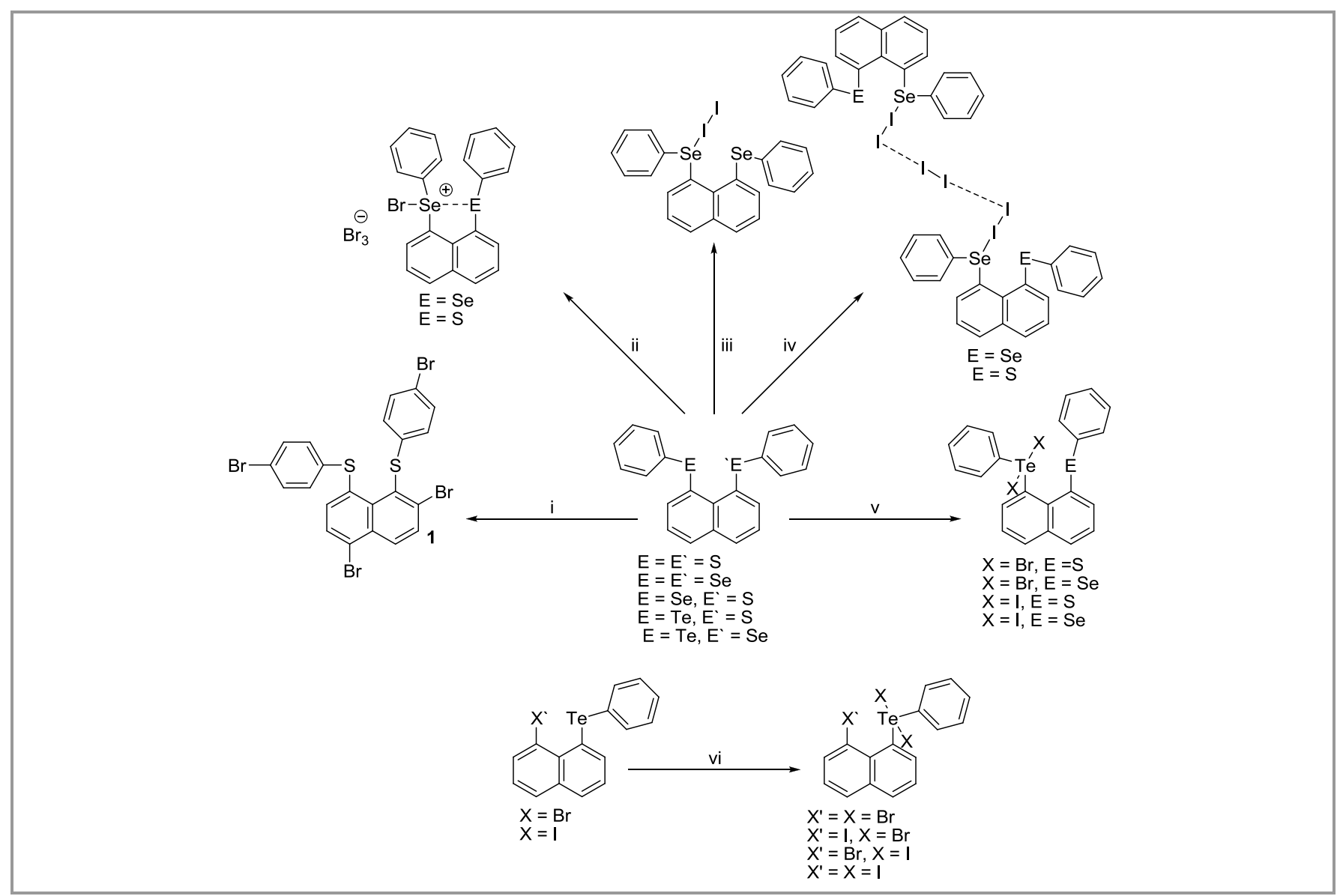

Scheme 7. Synthesis of halogen adducts. Conditions: i-vii $\mathrm{X}_{2}(\mathrm{X}=\mathrm{Br}, \mathrm{I}), \mathrm{CH}_{2} \mathrm{Cl}_{2}, 2$ h, $\mathrm{RT}$ : i (4 equiv) $\mathrm{Br}_{2}$; ii (2 equiv) $\mathrm{X}_{2}$; iii/iv (1 equiv) $\mathrm{I}_{2}$; v/vi (1 equiv) $\mathrm{X}_{2}$.

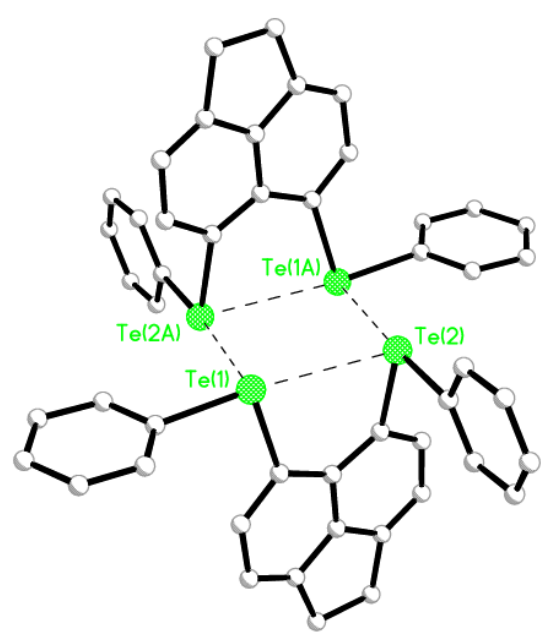

Figure 6 The $\mathrm{X}$-ray structure of acen $(\mathrm{TePh})_{2}$; short intermolecular contacts between neighbouring molecules form planar $\mathrm{Te}_{4}$ rhombus units

The propensity of group sixteen elements to catenate is illustrated neatly in the X-ray structure of acen $(\mathrm{TePh})_{2}$ Short intermolecular contacts operating between neighbouring molecules of this bis-telluride construct $\mathrm{Te}_{4}$ parallelograms. As a consequence of the symmetry, the $\mathrm{Te}_{4}$ rhombus core is strictly planar containing two unequal $\mathrm{Te} \cdots \mathrm{Te}$ non-bonded distances and with interior angles combining to $360^{\circ}$. The larger intermolecular separation (3.853(1) $\AA$ ) is longer than the non-bonded intramolecular peri-distance (3.3674(19) $\AA$ ), though both are shorter than twice the van der Waals radius of tellurium (4.12 $\AA$ ) (Figure 6).

I hope it is clear from the above that the late $80 \mathrm{~s}$ and early 90 s helped develop a number of themes that have carried threaded through our research. Paul Wood was also responsible for the start of our interest in P-Se chemistry. The organic-P-S chemistry developed well but the attraction of P-Se chemistry was enormous, the opportunity to make use of ${ }^{77} \mathrm{Se}$ $\mathrm{nmr}$ proved irresistible. $\mathrm{We}^{37}$ set about reacting cyclophosphines with selenium in efforts to form analogues of the more well known sulfur systems. In parallel (but unknown to us) Karaghiosoff was developing related systems. ${ }^{38} \mathrm{We}$ found that cyclophosphines react under mild conditions to give a variety of P-Se heterocycles (scheme 8 ) and that the outcome could be influenced by adjusting the stoichiometry of the reaction. The P-Se heterocycles represent simple valence isoelectonic replacement of $\mathrm{RP}$ by Se and oxidation of $\mathrm{P}(\mathrm{III})$ centres to $\mathrm{P}(\mathrm{V})=\mathrm{Se}$ centres. The four membered rings were a possible 
anticipated product though to date no one has been able to directly react $\mathrm{P}_{4} \mathrm{Se}_{10}$ with $\mathrm{RH}$ to give these analogues of Lawesson's reagent. In general we restricted ourselves to reactions with phenyl phosphines since we found reactions with eg $(\mathrm{PMe})_{\mathrm{x}}$ systems are extremely comple ${ }^{39}$ whilst Karaghiosoff tested the reactions with a wider range of alkyl phosphines (scheme 8).

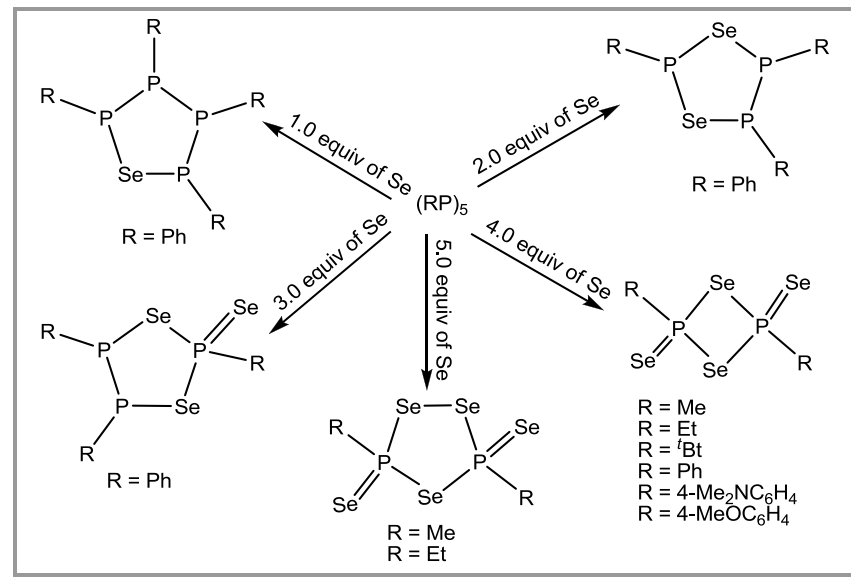

Scheme 8 Examples of syntheses of P-Se heterocycles. ${ }^{37,38}$

In 1988 we established the syntheses of some new PSe heterocycles and largely characterized them by multielement NMR. ${ }^{37}$ However, this preliminary work was not complete. The early organic reactivity was tested using a solution of (1) in scheme 9 and showed immediate promise with two new organo -P-Se heterocycles being isolated and characterized crystallographically. ${ }^{37}$ Emboldened by our exciting results I submitted abstracts on both M-S-N and P-Se chemistry to the $5^{\text {th }}$ Inorganic Rings International Symposium in Amherst. Whilst my presentation on M-S-N chemistry went well I was rather dismayed to sit through a lecture by Karagiosoff which summarized at least half of my groups work in the area. I hastily rewrote my overheads and presented somewhat different material but this was a serious shock and salutary warning as to the need to publish or perish!

After our initial flurry of activity we quickly established a synthesis that gave pure $\mathrm{PhP}(\mathrm{Se})(\mu$ $\left.\mathrm{Se}_{2}\right) \mathrm{P}(\mathrm{Se}) \mathrm{Ph}$ and prepared $^{40}$ an example of a coordination compound by reaction with $\mathrm{Pt}(\mathrm{dppe}) \mathrm{Cl}_{2}$ but then there set this system to one side. In 1994 I moved, along with Alex Slawin (and our three children) to Loughborough. At that time there was little interest in funding P-Se chemistry from UK research councils and our work moved on to imidophosphinate ligands ${ }^{41}$ including synthesizing the first six membered true heterocycle..(ie a hetrocycle in which every atom is different, ${ }^{, 42}$ and ferrocenyl analogues of Lawesson's reagent. ${ }^{43}$

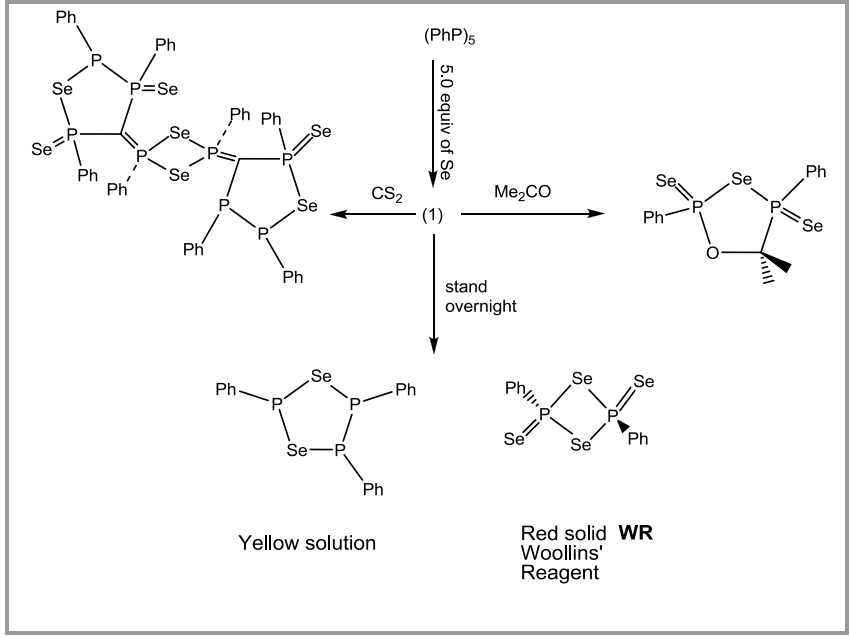

Scheme 9 Early syntheses and organic reactivity developed at Imperial College. ${ }^{37}$

Our interest and enthusiasm was, however, suddenly reawakened when Tony Hill, an ex colleague from Imperial College, published a manuscript with the tongue in cheek title 'Selenoketenyl and selenoalkyne complexes via the reactions of ketenyl complexes with Woollins' reagent' ${ }^{44}$ This paper decribed the transformation of some organometallic complexes to their selenium analogues. Although the organic $\mathrm{C}=\mathrm{O}$ group was converted to $\mathrm{C}=\mathrm{Se}$ the coordinated $\mathrm{CO}$ remained unchanged (eqn 6).

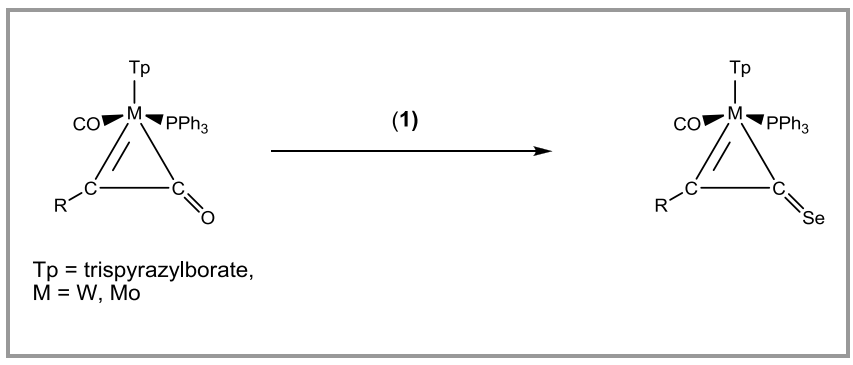

Equation 6

This paper by Hill suggested that the four membered ring system should be called Woollins' reagent WR and reactivated our interest and within a week a proposal was submitted to the EPSRC seeking funds to develop the chemistry of 'this important system'. Luckily, almost certainly because of the Hill paper, this was funded and we set about establishing the nature and the utility of this new material.

Our work developed syntheses of ring systems and established that WR was the active species in reactions that had already been reported. We also found that WR was the most readily isolated heterocyle and so this soon became the main focus of our work. A major obstacle to developing the chemistry of WR was the unwieldy synthesis from the (incredibly smelly) cyclophosphine whose preparation could not be readily scaled up.

Leaning on our previous work in liquid ammonia we prepared $\mathrm{Na}_{2} \mathrm{Se}$ by simple reduction of selenium with sodium in liquid ammonia to give material which is 
much more soluble than that prepared by the solid state route though it is worth noting that this wonderfully finely divided solid is also very pyrophoric; on one occasion around $75 \mathrm{~g}$ caught fire in the port of our glove box with rather unpleasant consequences. Reaction of $\mathrm{Na}_{2} \mathrm{Se}$ with $\mathrm{PhPCl}_{2}$ gives a mixture of five membered rings (scheme 10) which can be converted to WR by reaction with grey selenium. $^{45}$

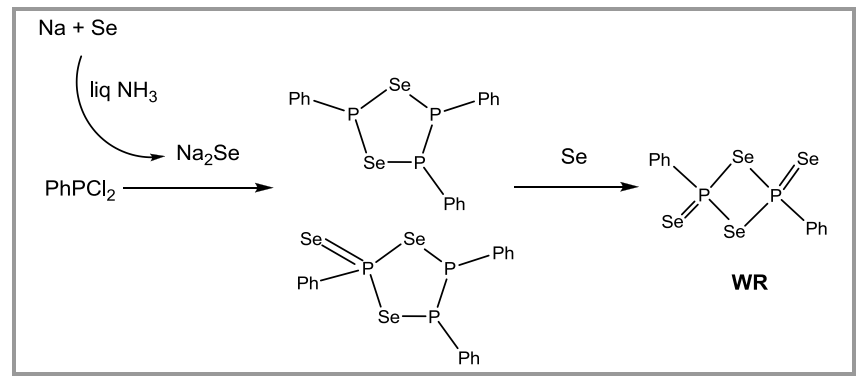

Scheme 10 Large scale synthesis of WR capable of scale up to ca 150 $\mathrm{g}$ in normal lab glassware.

We extended this preparative route to ferrocenyl systems and also obtained even more selenium rich heterocycles both directly and by conversion from WR (scheme 11). ${ }^{46}$

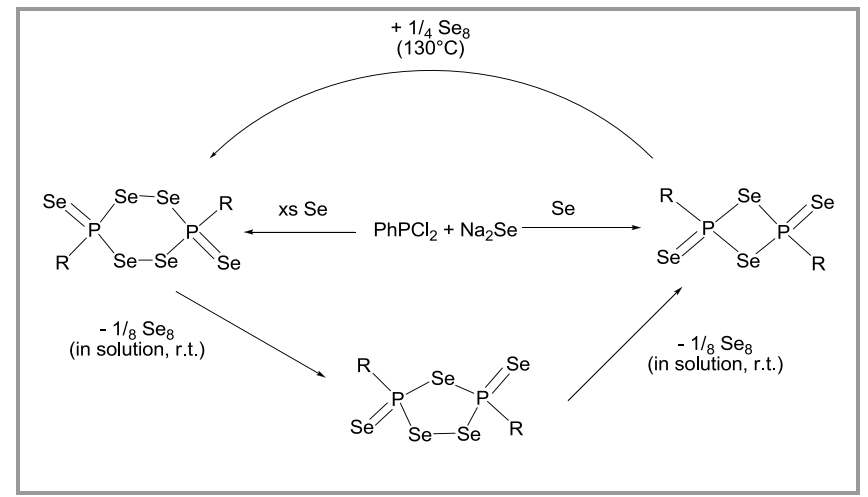

Scheme 11 Formation of selenium rich $\mathrm{P}-\mathrm{Se}$ heterocycles $\mathrm{R}=\mathrm{Ph}$, Fc.

In subsequent work we studied the formation of carbon substituted analogues ${ }^{47}$ starting from organocyclophosphines (scheme 12).

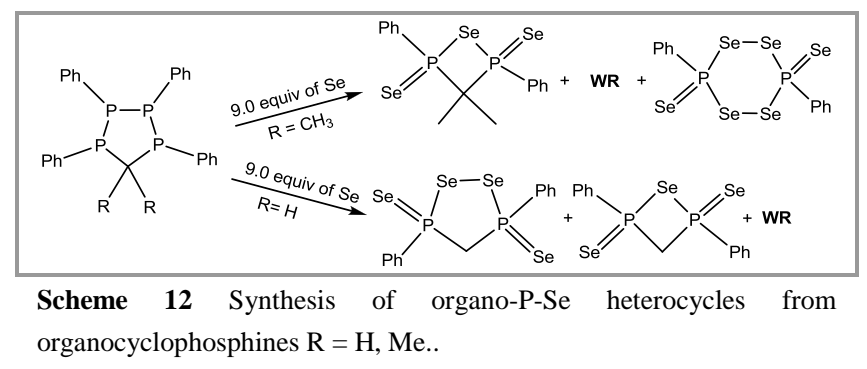

The reactivity of Woollins' reagent in many respects mirrors that of Lawesson's reagent except that often the resulting organo-selenium compounds rapidly react to form new species. In the following there is a summary of different reaction types but no discussion of metal complex formation though Rothenberger has developed direct reactions of WR with metal salts to good effect ${ }^{49}$ and we have carried out some studies relating to our earlier work on ZDDP. ${ }^{50}$

We have reviewed the reactivity of WR previously ${ }^{51,52}$ and in the following provide a brief summary together with more recent results.

Selenoamides ${ }^{53,54}$ and selenoaldehydes ${ }^{55}$ have been obtained by simple oxygen/selenium exchange or reaction with arylnitriles (ArCN) followed by hydrolysis. Thus the reaction of WR with arylnitriles in refluxing toluene followed by addition of water gives primary arylselenoamides in $60-100 \%$ yield (eg eqn 7).

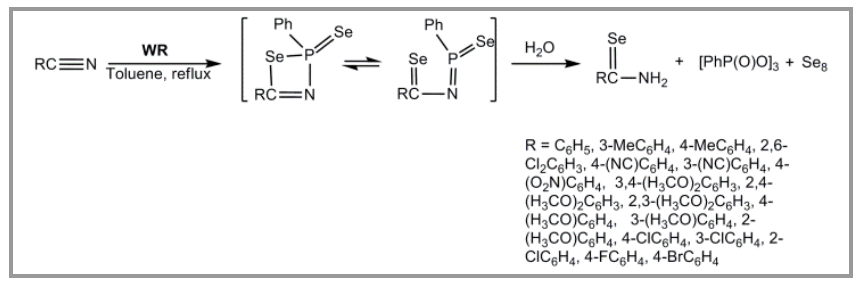

Equation 7

We examined the structural motifs and hydrogen bonding of selenoamides. ${ }^{56}$ Whilst $\mathrm{H}$-bonding is well understood in amides the heavier chalcogenides are less well studied. We broadly classified the pattern of hydrogen bonding in compounds A - L (selected parameters in Table 1) with illustrative examples in Figure 7. The H-bonding can be classified (1) A: Ladder; (2) B: Linked dimer; (3) F: Tetrameric sheets; (4) G: Herringbone dimers; (5) I: Helical chains and (6) $\mathbf{J}$ : Linear chains. It is clear that N$\mathrm{H} \cdots$ Se hydrogen bonding is an important feature of the solid state packing of these molecules and may be a significant influence in biological systems

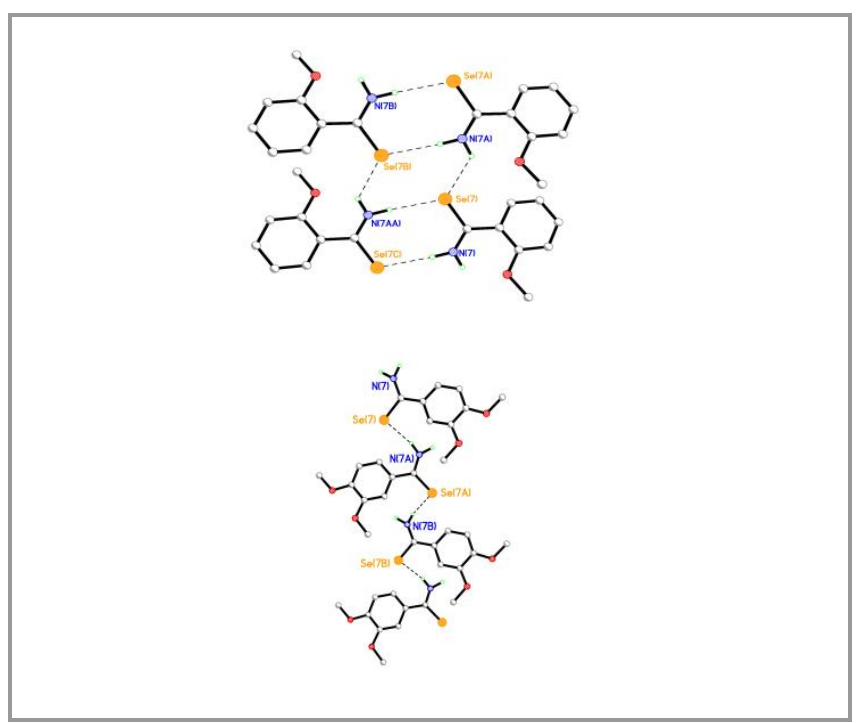

Figure 7 Examples of $\mathrm{N}-\mathrm{H}$..Se bonding patterns in selenoamides., upper Compound A: Ladder, lower, Compound J: Linear chains 
Table 1. Major N-H $\cdots$ Se hydrogen bonding distances $(\AA)$ in selenoamides.

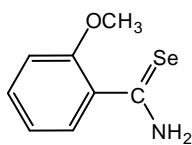

A

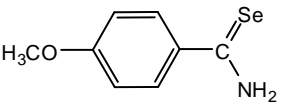

$\mathbf{E}$

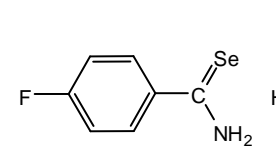

I

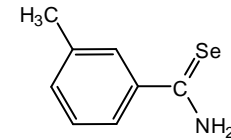

B<smiles>COc1cccc(C(N)=[Se])c1</smiles>

C

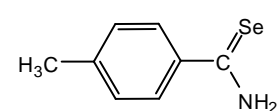

D<smiles>N#Cc1ccc(C(N)=[Se])cc1</smiles>

G

$\mathrm{H}$

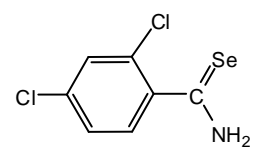

$\mathbf{L}$

\begin{tabular}{|c|c|c|c|c|c|c|c|}
\hline & Type & Se...H & Se...N & Se...H-N & Se...H & Se...N & Se...H-N \\
\hline $\mathbf{A}$ & Ladder & $2.55(1)$ & $3.512(3)$ & $167(3)$ & $2.72(4)$ & $3.403(3)$ & $127(3)$ \\
\hline B & Linked dimers & $2.527(7)$ & $3.489(2)$ & $168(2)$ & $2.539(10)$ & $3.491(2)$ & 164(3) \\
\hline C & Linked dimers & $2.59(3)$ & $3.510(6)$ & $156(6)$ & $2.58(3)$ & $3.491(5)$ & $155(5)$ \\
\hline D & $\begin{array}{l}\text { Linked dimers } \\
\text { (sheets) }\end{array}$ & $2.55(1)$ & $3.517(4)$ & $170(5)$ & $2.71(5)$ & $3.408(4)$ & $129(4)$ \\
\hline $\mathbf{E}$ & $\begin{array}{l}\text { Linked dimers } \\
\text { (sheets) }\end{array}$ & $2.55(7)$ & $3.527(4)$ & $174(4)$ & $2.82(5)$ & $3.415(4)$ & $120(4)$ \\
\hline \multirow[t]{2}{*}{$\mathbf{F}$} & Tetramers (sheets) & $2.57(2)$ & $3.58(11)$ & 171(11) & $2.63(6)$ & $3.527(11)$ & $152(11)$ \\
\hline & & $2.90(14)$ & $3.430(12)$ & $115(1)$ & $2.69(10)$ & $3.466(10)$ & $136(10)$ \\
\hline G & Herringbone dimers & $2.68(10)$ & $3.502(8)$ & $142(12)$ & $2.85(12)$ & $3.509(8)$ & $125(1)$ \\
\hline \multirow[t]{2}{*}{ H } & Dimers & $2.50(17)$ & $3.43(4)$ & $158(4)$ & $2.49(16)$ & $3.43(3)$ & $160(4)$ \\
\hline & & $2.48(9)$ & $3.45(5)$ & $169(5)$ & $2.58(8)$ & $3.43(3)$ & $169(5)$ \\
\hline \multirow[t]{2}{*}{ I } & Helical chain & $2.63(3)$ & $3.513(5)$ & $150(4)$ & $2.97(3)$ & $3.628(5)$ & $125(4)$ \\
\hline & & $2.74(4)$ & $3.566(5)$ & $143(5)$ & $2.62(3)$ & $3.512(5)$ & $151(5)$ \\
\hline $\mathbf{J}$ & Chain & $2.52(2)$ & $3.483(6)$ & $168(6)$ & & & \\
\hline $\mathbf{K}$ & Dimers & $2.69(1)$ & $3.63(3)$ & $162(3)$ & & & \\
\hline $\mathbf{L}$ & Linked dimers & $2.535(8)$ & $3.511(4)$ & $174(5)$ & $2.579(14)$ & $3.533(4)$ & $165(4)$ \\
\hline
\end{tabular}

In contrast to the original reactions we studied for the formation of selenoketones we observed self-coupling of a wide range of ketones and aldehydes was achieved by treatment with WR in refluxing toluene, which yields symmetrical and unsymmetrical $(E)$ olefins in high yield (Scheme 13). The method has potential for a variety of systems and may prove especially beneficial where base sensitive substituents are present. Its speculative mechanism involves a Wittig-like reaction intermediate rather than a decomposition of a selenoketone. ${ }^{57}$

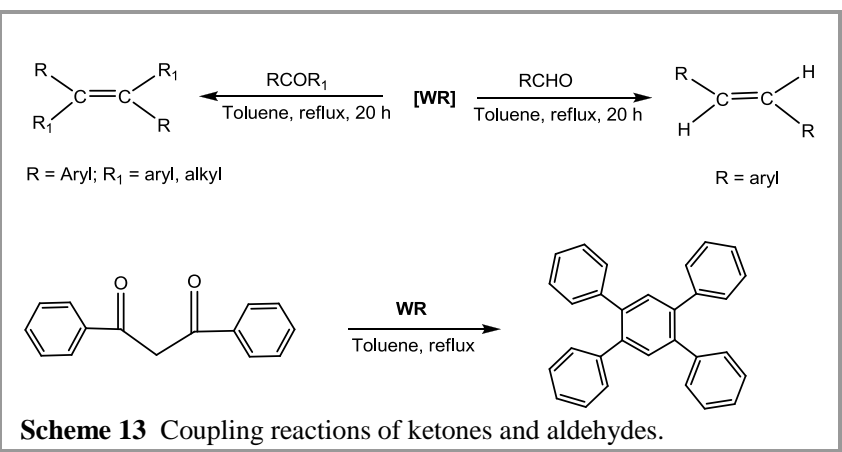




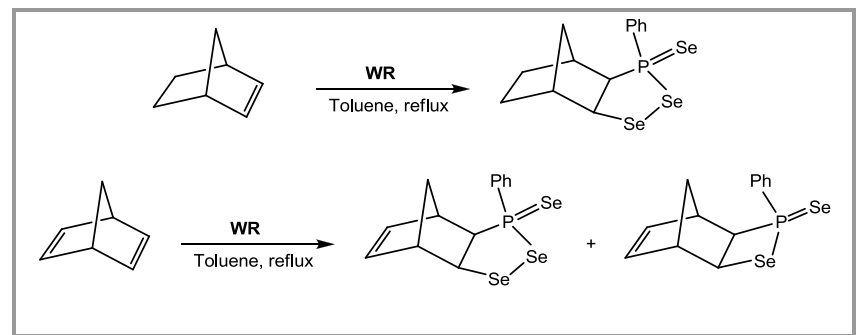

Scheme 14

WR undergoes a wide range of cycloaddition reactions and we have already mentioned the reaction with acetone and carbon disulfide (scheme 9). WR reacts with trinorbornene in refluxing toluene to give a five-membered $\mathrm{C}_{2} \mathrm{PSe}_{2}$ ring (confirmed by X-ray crystallography). ${ }^{58}$ However, reaction of $\mathbf{W R}$ with trinorboradiene yields the five-membered $\mathrm{C}_{2} \mathrm{PSe}_{2}$ ring and a four-membered $\mathrm{C}_{2} \mathrm{PSe}$ heterocycle analogous to the thiaphosphetane $\left(\mathrm{C}_{2} \mathrm{PS}\right)$ rings (Scheme 14). ${ }^{43}$ Reaction of WR with azobenzene ${ }^{58}$ gives a $\mathrm{PSe}_{2} \mathrm{~N}$ heterocycle (eqn 8)

$$
\mathrm{Ph}-\mathrm{N}=\mathrm{N}-\mathrm{Ph} \underset{\text { Toluene, reflux }}{\mathrm{WR}}
$$

Eqn 8

Reaction of WR with alkynes has been extensively studied in particular by Pravat Bhattacharyya and Guoxong Hua and some key examples are summarized in scheme 15 . The reactions predominantly lead to five membered $\mathrm{C}_{2} \mathrm{PSe}_{2}$ rings. ${ }^{45,59}$ Refluxing WR with symmetrically disubstituted alkynes $(\mathrm{RC} \equiv \mathrm{C}-\mathrm{C} \equiv \mathrm{CR}, \quad \mathrm{R}=\mathrm{Ph}$, $\left.\mathrm{Si}\left(\mathrm{CH}_{3}\right)_{3}\right)$ in 2:1 molar ratio in toluene gave two product both containing five-membered $\mathrm{P}(\mathrm{Se}) \mathrm{Se}_{2} \mathrm{C}_{2}$ heterocycles either with one unreacted triple bond 'dangling' or bis-heterocycles with two fivemembered $\mathrm{P}(\mathrm{Se}) \mathrm{Se}_{2} \mathrm{C}_{2}$ rings are connected through a $\mathrm{C}-\mathrm{C}$ single bond. However, $\mathbf{W R}$ and ${ }^{\mathrm{t}} \mathrm{Bu}-\mathrm{C} \equiv \mathrm{C}-\mathrm{C} \equiv \mathrm{C}-$ ${ }^{\mathrm{t}} \mathrm{Bu}$ react differently to afford an unprecedented fourmembered $\mathrm{P}(\mathrm{Se}) \mathrm{SeC}_{2}$ heterocycle with one unreacted triple bond together with a fused bis-heterocycle containing two five-membered $\mathrm{P}(\mathrm{Se}) \mathrm{SeC}_{3}$ rings fused at the middle two carbons of the diyne to give a heteropentalene analogue of pentalene, [3.3.0]octa-16-diene (Scheme 15). ${ }^{60}$

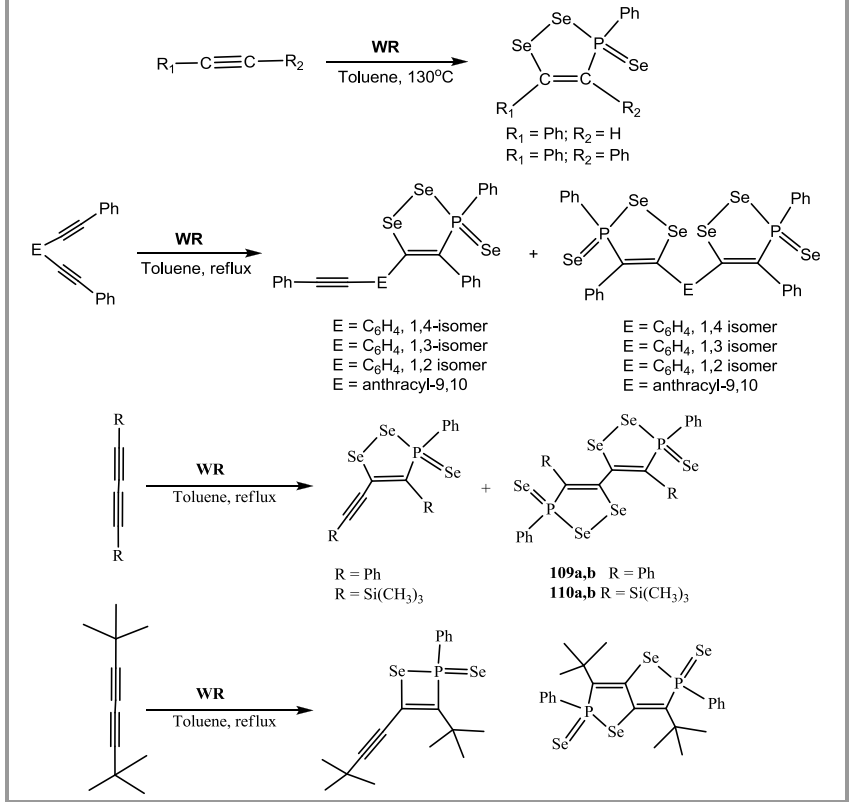

Scheme 15 Reaction of alkynes and dialkynes with WR

Refluxing a toluene solution of $\mathbf{W R}$ with a ten-fold excess of dialkylcyanamides $\mathrm{R}_{2} \mathrm{NCN}\left[\mathrm{R}_{2}=\mathrm{Me}_{2}\right.$, $\mathrm{CH}_{2} \mathrm{CH}_{2} \mathrm{OCH}_{2} \mathrm{CH}_{2^{-}}$, or $\left.-\left(\mathrm{CH}_{2}\right)_{5^{-}}\right]$led to fused ring $1,6,6 \gamma^{4}$-triselena-3a-phospha 3,4-diazapentalenes in ca. $5 \%$ yield (Scheme 16). ${ }^{61}$

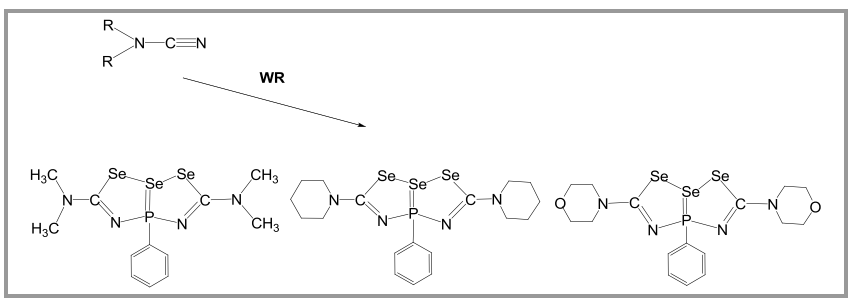

Scheme 16

Selenophenes $^{62}$ (and related 2,5-Disubstituted 1,3,4selenadiazoles $^{63}$ ) can be obtained by direct reaction of the diketone (or the diamide) with WR or via the treatment of $O$-methyl $S e$-hydrogen phenylphosphonodiselenoate with arylacetylenes

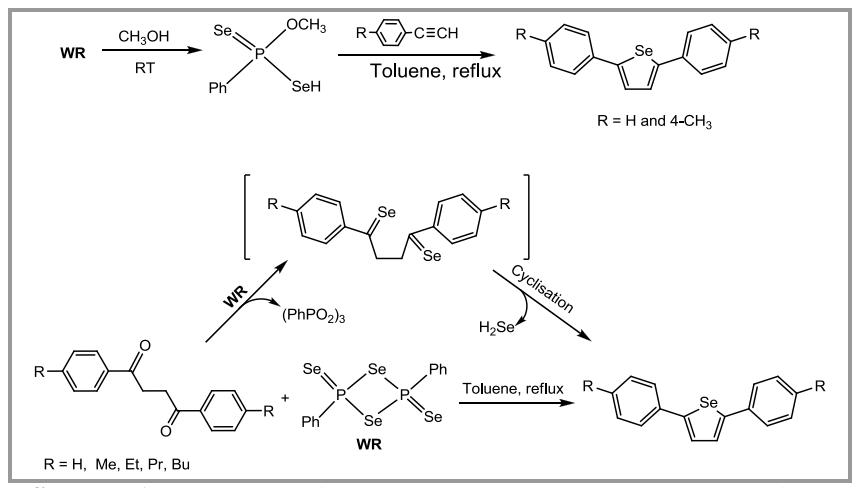

Scheme 17 Synthesis of 2,5-Diarylselenophenes by reaction of $O$ methyl $\mathrm{Se}$-hydrogen phenylphosphonodiselenoate with arylacetylenes or by direct reaction of Woollins' reagent with 1,4-diarylbutane-1,4diones. 
Other simple heterocycles can be readily formed from diols or diamines Thus, treatment of WR with 2aminophenol, 1,2-phenylene-diamine, catechol or 3,4diaminotoluene gives the simple 5-membered heterocycles (eqn 9) formed by asymmetric cleavage of the selenium compound. ${ }^{64}$

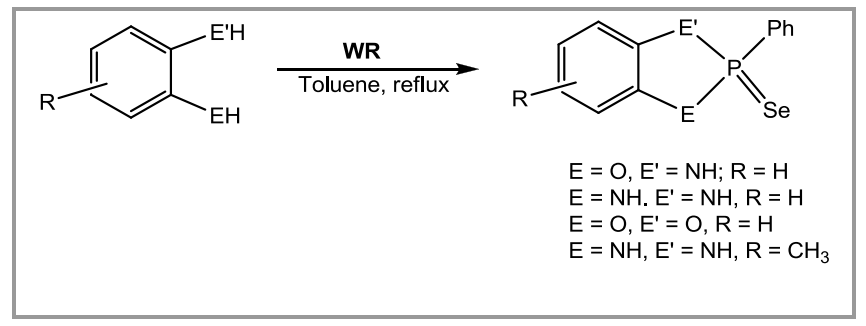

Eqn 9

Cleavage of the four-membered $\mathrm{P}_{2} \mathrm{Se}_{2}$ ring in $\mathbf{W R}$ by alkyl diols affords the bisdiselenophosphonic acids quantitatively, the latter can be converted into the corresponding ammonium salts by treatment with butyl amine, followed by addition of $\mathrm{I}_{2} / \mathrm{KI}$ to give eight-, nine- and ten-membered ring diselenides in good to excellent yield $(70-90 \%)$ (Scheme 18), examples of each of these rings were characterized crystallographically (Figure 8 ). ${ }^{65}$

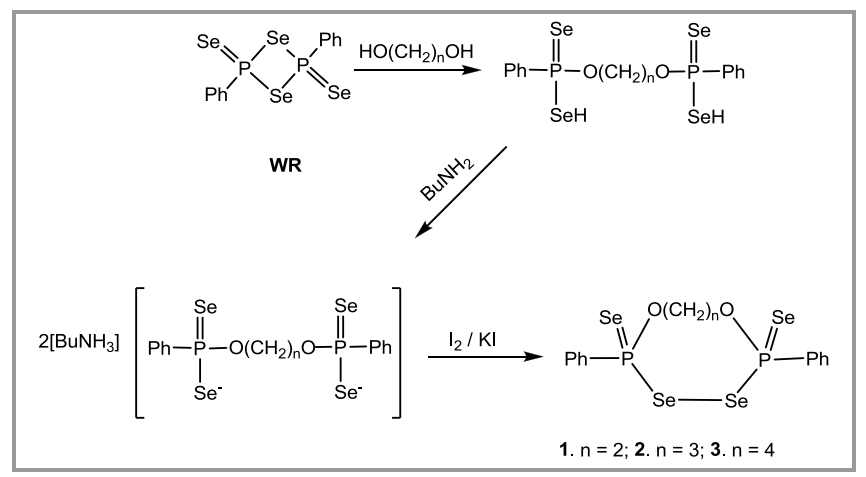

Scheme 18

Interestingly these large rings are readily converted to smaller rings by elimination/reaction of a $\mathrm{PhPSe}_{2}$ unit (eqn 10).

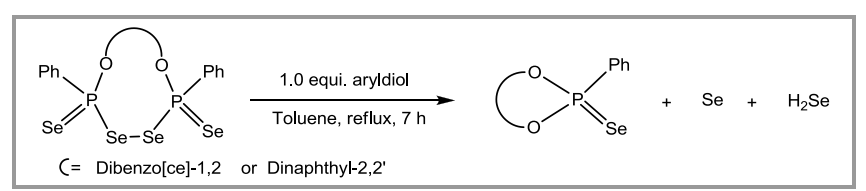

Eqn 10

It is interesting to consider the difference in reactivity between WR and Lawesson's Reagent (LR). Nphenylglycine reacts with an equivalent of WR to give as the major product planar 1,4-diphenylpiperazine2,5-diselenone and as the minor product boat conformation1,4-diphenyl-5-selenoxopiperazin-2-one.

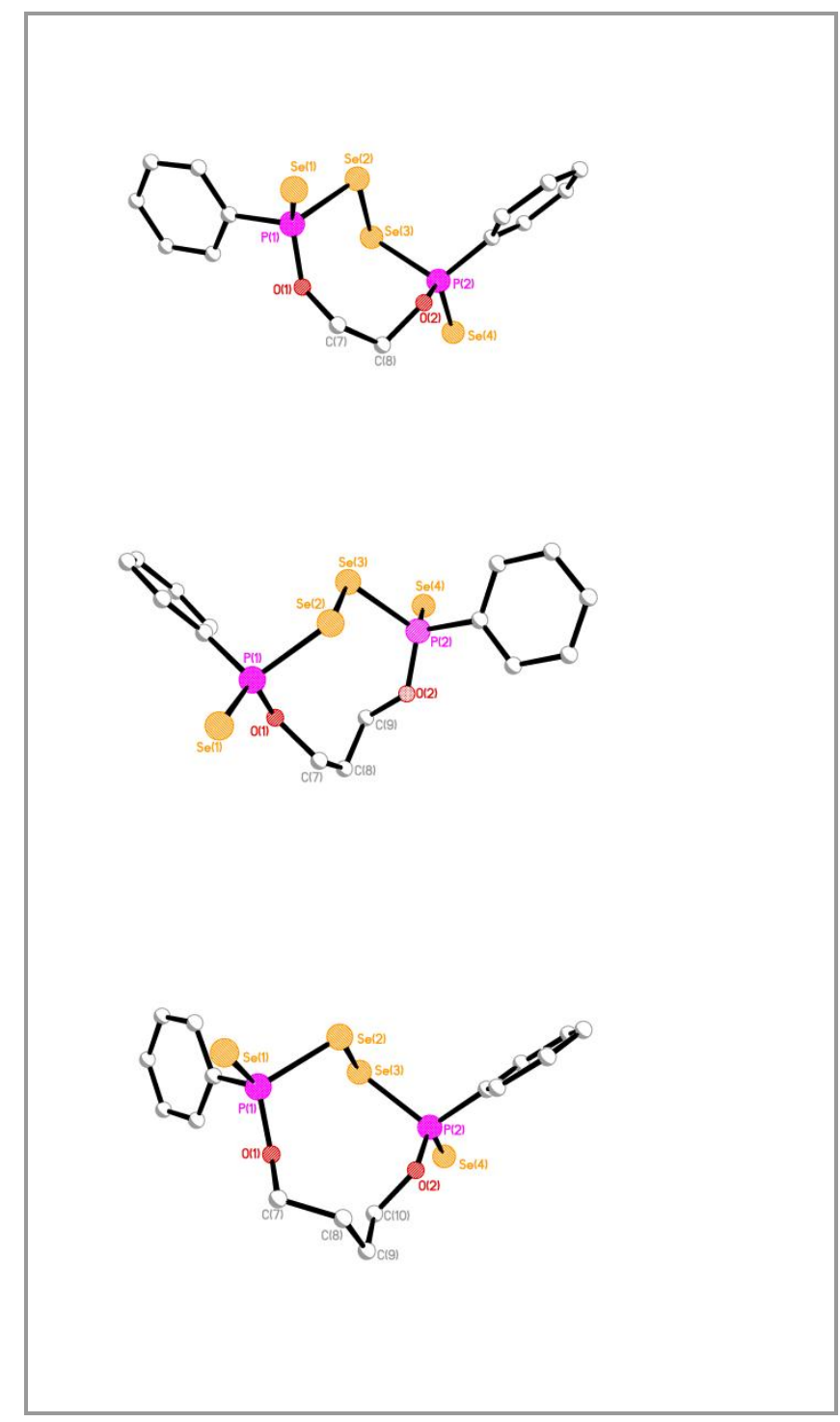

Figure 8 X-rays structures of 8,9 and 10 membered heterocycles ${ }^{65}$

DFT-B3LYP calculations suggest that the planar conformation is around $2 \mathrm{kcal} / \mathrm{mol}$ less stable than the puckered conformation for the dideleno derivative. In contrast to WR, reacting N-phenylglycine with an equivalent of $\mathbf{L R}$ gives1,4-diphenylpiperazine-2,5dithione and N-phenyl-2(phenylamino)ethanethioamide. Surprisingly, 2phenylglycine treated with an equivalent of WR under identical reaction conditions leads to only the formation of 2,5-diphenylpyrazine. ${ }^{67} \mathrm{We}$ also examined the reaction of $\mathbf{W R}$ and $\mathbf{L R}$ with diphenylcyclopropenone, where there is opportunity for reaction at the $\mathrm{C}=\mathrm{C}$ or the $\mathrm{C}=\mathrm{O}$ functionality. Interestingly, whilst LR simply thionated the substrate WR gave the selenketone derivative together with an unusual spirobicyclic system containing two four membered rings (eqn 11, Figure 9). ${ }^{45}$ 


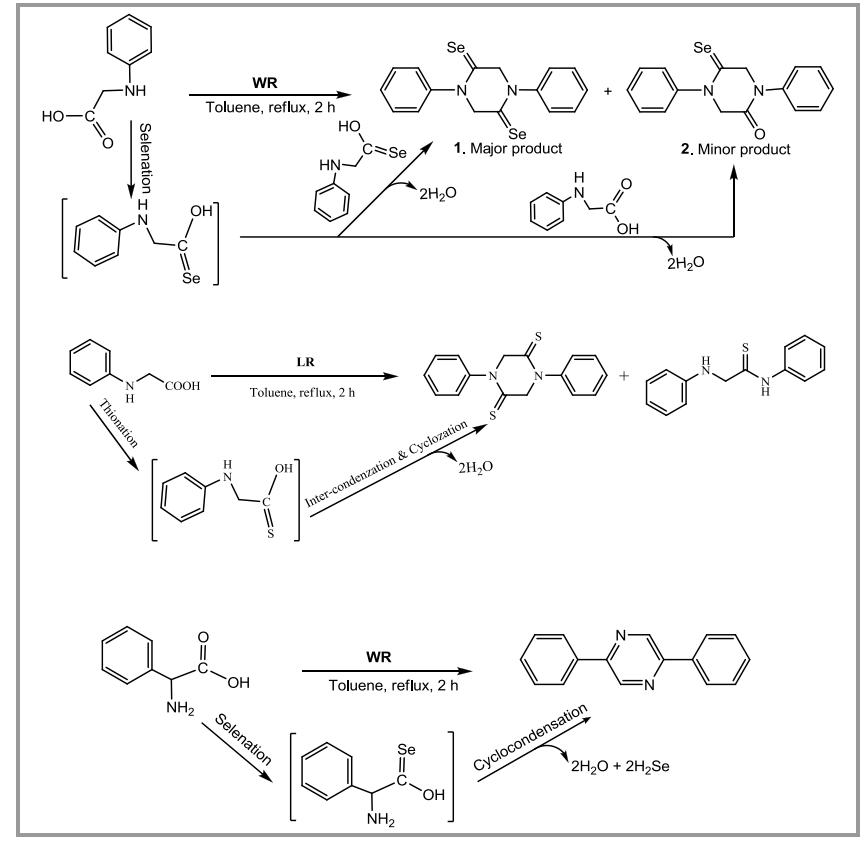

Scheme 19 Reaction of WR and LR with glycine and $N$ phenylglycine.

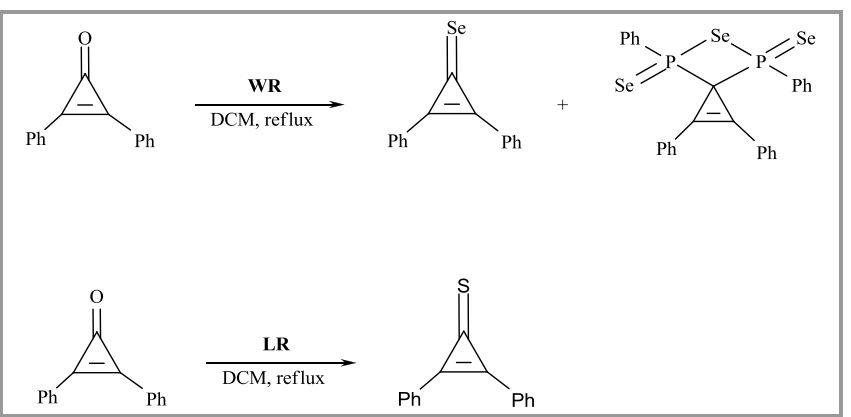

Eqn 11

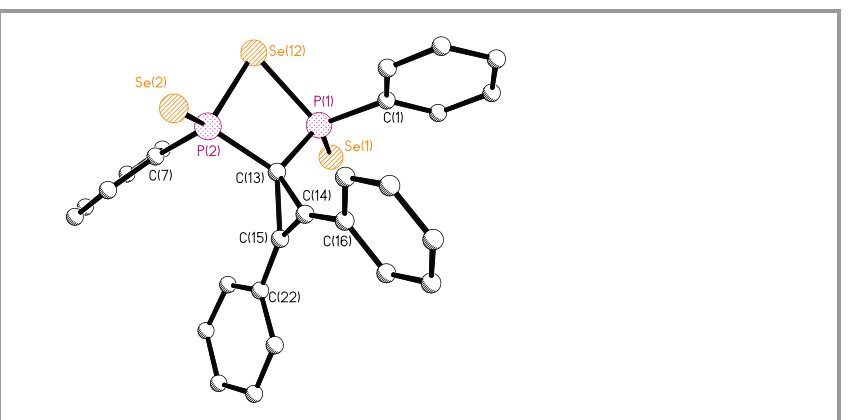

Figure 9 The X-ray structure of.the bicyclic product from eqn 11. Selected bond lengths $(\AA)$ and angles $\left({ }^{\circ}\right)$ : $\mathrm{P}(1)-\mathrm{Se}(1) 2.089(3), \mathrm{P}(1)-$ $\mathrm{Se}(12)$ 2.265(2), P(1)-C(1) 1.826(10), P(1)-C(13)1.840(9), C(13)C(15) $1.507(12), \quad \mathrm{C}(14)-\mathrm{C}(15), \quad 1.290(12) \mathrm{P}(1)-\mathrm{Se}(12)-\mathrm{P}(2)$ 78.83(9), $\mathrm{P}(1)-$ C(13)-P(2) 102.0(4).

One final example that deserves mention is the remarkable reaction of $\mathbf{W R}$ with secondary amines.

Reaction of WR with secondary amines in the presence of $\mathrm{CH}_{2} \mathrm{Cl}_{2}$ or $\mathrm{CH}_{2} \mathrm{Br}_{2}$ proceeds to give, predictably, $\operatorname{Bis}(N, N$-dialkyl- $P$ phenylphosphonamidodiselenoates (scheme 20). More excitingly, we also obtained the new heterocycle $1,2,4,5,7,8,10,11$-octaselenacyclododecane ${ }^{68}$

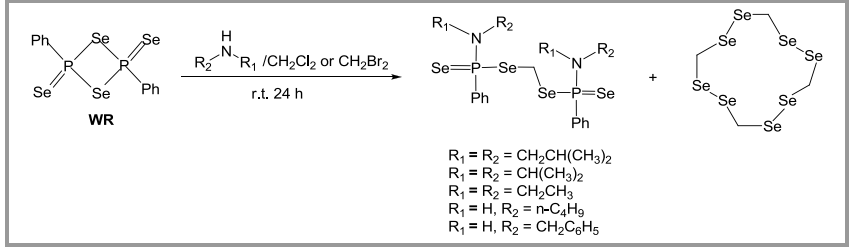

Scheme 20

The new 12-membered $\mathrm{C}_{4} \mathrm{Se}_{8}$ ring is remarkably stable and even when heated does not eliminate selenium. Interestingly, in the structure of (Figure 10) the $\mathrm{Se}(2)$ atom lies over the face of the central $\mathrm{Se}_{2} \mathrm{C}$ unit with an $\operatorname{Se}(2) . . \operatorname{Se}(1 \mathrm{~A})$ distance of $3.880(2) \AA$

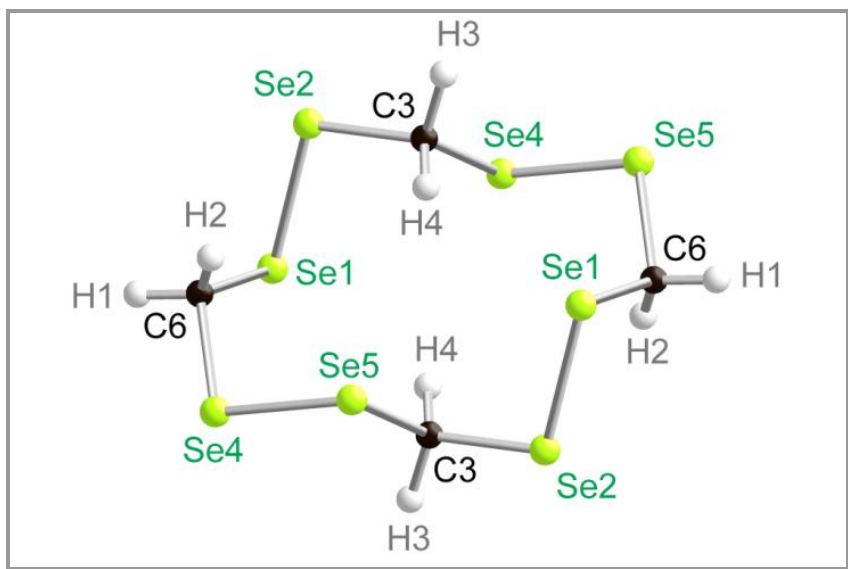

Figure $\mathbf{1 0}$ The X-ray structure of $1,2,4,5,7,8,10,11$ octaselenacyclododecane. Selected bond lengths $(\AA)$ and angles $\left({ }^{\circ}\right)$ : $\mathrm{Se}(1)-\mathrm{Se}(2)$ 2.3162(9), $\mathrm{Se}(4)-\mathrm{Se}(5)$ 2.3094(8), $\mathrm{Se}(2)-\mathrm{C}(3)$ 1.931(5), $\mathrm{Se}(1)-\mathrm{C}(6) 1.945(5), \mathrm{Se}(5)-\mathrm{C}(6)$ 1.940(5), Se(4)-C(3) 1.954(5); C(6)$\mathrm{Se}(1)-\mathrm{Se}(2)$ 102.04(16), C(3)-Se(2)-Se(1) 100.06(17), $\mathrm{Se}(2)-\mathrm{C}(3)-\mathrm{Se}(4)$ 112.2(3), C(3)-Se(4)-Se(5) 100.79(17), C(6)-Se(5)-Se(4) 99.80(16), $\mathrm{Se}(5)-\mathrm{C}(6)-\mathrm{Se}(1) 106.7(2)$.

In conclusion, this review has aimed to demonstrate the non linear nature of research and the enjoyment that an unexpected diversion might engender. The utility of Woollins' reagent is established and it is reasonable to anticipate that more unusual reactions will be developed with this system since it is now sold commercially. Current work in our laboratories includes studies into WR and efforts to prepare stable P-Te systems. 


\section{Acknowledgment}

I am grateful to the many researchers at all levels, who have contributed to this work. Special acknowledgement has to go to Prof Alexandra Slawin who is the finest crystallographer I have ever met.

\section{References}

(1) Goehring, M., Debo, A. Z.anorg.allgm.chemie, 1953, $273,319$.

(2) Daum, K.W., Goehring, M, Weiss, J Z.anorg.allgm.chemie, $1955,278,260$.

(3) Piper, T.S., J.Amer.Chem.Soc., 1958, 80, 30.

(4) Woollins, J.D., Grinter, R., Johnson, M.K., Thomson, A.J., JCS Dalton Trans, 1980,1910.

(5) Powell, D.B., Woollins, J.D., Spectrochim Acta, 1980, A36, 447.

(6) (a) Ghosh, A. K.; Bilcer, G.; Schiltz, G. Synthesis 2001, 2203. (b) List, B.; Castello, C. Synlett 2001, 1687.

(7) Irgolic, K. J. In Houben-Weyl, 4th ed., Vol. E12b; Klamann, D., Ed.; Thieme: Stuttgart, 1990, 150.

(8) For a review see: Labes, M.M., Love, P., Nichols, L.F. Chem Rev., 1979, 79,1.

(9) Chivers, T., Chem.Rev., 1985, 85, 341.

(10) A Guide to Chalcogen-Nitrogen Chemistry, Chivers, T., World Scientific, Singapore,2005.

(11) Morris, J.L., Rees, C.W., Chem.Soc.Rev., 1986,1 (b) Rees, C.W., J.Heterocycl..Chem., 1992, 29,639

(12) .Nikonov,G.N., Balueva,A.S. in Comprehensive Heterocyclic Chemistry II, Vol 9., Ed Katrisky,A.R., Rees, C.W., Scriven, E.F.V., vol ED Newkome, G.R., Pergamon/Elsevier, Oxford, 1996

(13) Kelly, P.F., Woollins, J.D., Polyhedron, 1986,5,607.

(14) Chivers, T., Edelmann,F., Polyhedron, 1986,5,1661.

(15) Kelly, P.F.,Slawin, A.M.Z., Williams, D.J., Woollins, J.D. Chem.Soc.Rev., 1992, 246.

(16) Jones, R., Kelly, P.F., Warrens, C.P., Williams, D.J., Woollins, J.D. J. Chem. Soc., Chem. Comm., 1986, 711(b) Jones, R., Warrens, C.P., Williams, D.J., Woollins, J.D. J. Chem. Soc., Dalton Trans., 1987, 907(c) Jones, R., Kelly, P.F., Williams, D.J., Woollins, J.D. J. Chem. Soc., Dalton Trans., 1988, 803

(17) Kelly, P.F., Slawin, A.M.Z., Williams, D.J., Woollins, J.D. J. Chem. Soc., Chem. Commun., 1989, 408 (b) Kelly, P.F., Parkin, I.P., Slawin, A.M.Z., Williams, D.J., Woollins, J.D. Angew. Chem. Int. Ed. Engl., 1989, 28, 1047 (c) Kelly, P.F., Slawin, A.M.Z., Williams, D.J., Woollins, J.D.Polyhedron, 1990,9, 1567.

(18) Kelly, P.F., Slawin, A.M.Z., Williams, D.J., Woollins, J.D Angew. Chem. Int. Ed. Eng., 1992, 31, 616.

(19) Kelly, P.F., Slawin, A.M.Z., Williams, D.J., Woollins, J.D, Polyhedron, 1991,10,2337 (b) Ginn, V.C., Kelly, P.F., Slawin, A.M.Z., Williams, D.J., Woollins, J.D, JCS Dalton Trans,1992, 963.

(20) Roesky, H.W., Rao, M.N.S., Nakajima, T., Sheldrick, W.S. Chem. Ber., 1979, 112, 3351

(21) Belton, P.S., Ginn, V.C., Kelly, P.F., Woollins, J.D, JCS Dalton Trans, 1992, 1135.

(22) Menzer,S., Phillips, J.R., Slawin,A.M.Z., Williams,D.J.,Woollins, J.D. JCS Dalton, 2000,3269
(23) Phillips, J. R., . Poat, J.C., Slawin, A.M.Z., Williams, D.J., Wood, P.T., Woollins, J.D. J. Chem. Soc., Dalton Trans. 1995, 2369

(24) Poat, J.C., Slawin, A.M.Z., Williams, D.J., Wood, P.T., Woollins, J.D J. Chem. Soc., Chem. Commun., 1990, 1036

(25) Poat, J.C., Slawin, A.M.Z., Williams, D.J., Wood, P.T., Woollins, J.D. Polyhedron, 1992, 11,2125.

(26) Belton, P.S., Parkin,I.P., . Williams, D.J. Woollins, J.D. J. Chem. Soc., Chem. Commun., 1988, 1479 (b) Parkin,I.P., . Williams, D.J. Woollins, J.D. J. Chem. Soc., Chem. Commun, 1989, 58 (c) Parkin, I.P., Woollins, J.D. J. Chem. Soc., Dalton Trans., 1990, 925. (27) Jagg, P. N., . Kelly, P.F., . Rzepa, H.S., . Williams, D.J., Woollins, J.D., Wylie, W. J. Chem. Soc., Chem. Commun., 1991, 942

(28) Meisel, M. Grunze, G. Z. Anorg. Allg. Chem., 1970,373,265

(29) Slawin,A.M.Z., Williams, D.J., Wood, P.T., Woollins, J.D. J. Chem. Soc., Chem. Commun., 1987, 1741

(30) Kilian,P. Knight, F.R., Woollins, J.D. Chem.Eur.J., 2011, 17,2302 (b) Kilian,P. Knight, F.R., Woollins, J.D., Coord Chem Rev, 2011,255, 1387.

(31) Kilian, P., Philp, D., Slawin, A.M.Z., Woollins,J.D., Eur J.Inorg.Chem, 2003, 249

(32) Kilian, P., Slawin, A.M.Z., Woollins,J.D., ChemEur J, $\mathbf{2 0 0 3}, 9,215$.

(33) Kilian, P., Slawin, A.M.Z., Woollins,J.D. Chem Comm 2003, 1174 (b) Kilian, P., Milton, H.L., Slawin, A.M.Z., Woollins,J.D. Inorg Chem, 2004, 43, 2252.

(34) Kilian, P., Slawin, A.M.Z., Woollins,J.D. Dalton Trans. 2006, 2175 (b) Somisara, D.M.U.K., Bühl,M., Lebl, T., Richardson, N.V., Slawin, A.M.Z., Woollins, J.D., Kilian, P. Chem. Eur. J., 2010,17,2666.

(35) Knight, F.R., Fuller, A.R., Bühl, M., Slawin A.M.Z., Woollins, J.D. Chem.Eur.J. 2010, 16, 7503 (b) Knight, F.R., Fuller, A.R., Bühl, M., Slawin A.M.Z., Woollins, J.D. Chem. Eur. J, 2010, 16, 7605 (c) Knight, F.R., Fuller, A.R., Bühl, M., Slawin A.M.Z., Woollins, J.D. Chem. Eur. J, 2010, 16, 7617 (d) Knight, F.R., Fuller, A.R., Bühl, M., Slawin A.M.Z., Woollins, J.D. Inorg. Chem., 2010, 49, 7577.

(36) Aschenbach,L.K., Knight, F..R., Randall, R.A.M., Cordes, D.B., Baggott, A., Bühl, M., Slawin, A.M.Z., . Woollins, J.D. Dalton Trans., 2011, in press (b) Knight, F.R., Arachchige,K.S.A., Randall, R.A.M., ., Bühl, M., Slawin, A.M.Z., . Woollins, J.D., Dalton Trans., 2011, submitted.

(37) Fitzmaurice, J.C., Williams, D.J., Wood,P.T., Woollins, J.D. J. Chem. Soc., Chem. Commun. 1988, 741; (b) Wood,P.T., Woollins, J.D., J. Chem. Soc., Chem. Commun. 1988, 1190 (c) P Wood,P.T., Woollins, J.D, Phosphorus, Sulfur and Silicon 1989, 41, 51 (d) Pilkington, M.J., Slawin, A.M.Z., Williams, D.J Wood,P.T., Woollins, J.D Heteroatom chem. 1990, 1 , 351.

(38) a) Karaghiosoff, K, . Eckstein,K. Phosphorus, Sulfur and Silicon 1993, 75, 257 (b) Karaghiosoff, K. Eckstein, K., Motzer, Phosphorus, Sulfur and Silicon 1994, 93/94, 185 (c) Karaghiosoff, K. Habilitationschrift, University of Munich, 1997. (d)Großman, G., Ohms, G., Kruger, K.,. Karaghiosoff, 
K., Eckstein,K., Hahn, J., Hopp,A., Malkina,O.L., P Hrobarik, P. Z. Anorg. Allg. Chem. 2001, 627, 1269.

(39) Hall, S.W., Pilkington, M'J., Slawin, A.M.Z., Williams, D.J., Woollins, J.D. Polyhedron 1991, 10, 261.

(40) .Parkin,I.P., Pilkington, M.J., Slawin, A.M.Z., Williams, D.J., Woollins, J.D. Polyhedron, 1990, 9, 987.

(41) Woollins, J.D. J. Chem Soc., Dalton Trans. 1996, 2893.

(42) Ly, T.Q., Slawin, A.M.Z., Woollins, J.D., Angew. Chem. Int Ed. Engl. 1998, 37, 2501

(43) Foreman, .M. R. StJ,, Slawin A.M.Z., Woollins, J.D., J. Chem. Soc., Dalton Trans. 1999, 1175 (b) Foreman, .M. R. StJ,, Slawin A.M.Z.,Woollins, J.D., Dalton Trans.1996, 3653. (c) Foreman, .M. R. StJ,, Slawin A.M.Z.,Woollins, J.D., Chem. Comm., 1997, 1269; 1997, 855.

(44) .Baxter, I., Hill, A.F., Malget, J.M., White, A.J.P., Williams, D.J. Chem. Commun. 1997, 2049

(45) Gray,I.P., Bhattacharyya,P., Slawin, A.M.Z., Woollins,J.D., Chem. Eur. J. 2005, 11, 6221.

(46) Parveen, S., Kilian, P., Slawin, A.M.Z.,Woollins,J.D., Dalton Trans. 2006, 2586.

(47) Kilian,P., Slawin,A.M.Z., Woollins, J.D. Chem. Commun. 2001, 2288

(48) (a) Cava, M.P., Levinson, M.I. Tetrahedron 1985, 41, 5061; (b) Cherkasov, R. A. Kutyrev, G.A., . Pudovik, A.N.,Tetrahedron 1985, 41, 2567

(49) (a) Rothenberger, A., Shi, W., Shafaei-Fallah, M. Chem. Eur. J. 2007, 13, 5974 (b) Shi, W., Shafaei-Fallah, M., Rothenberger, A Chem. Comm. 2007, 4255 (c) Shi, W., . Zhang, L., . Shafaei-Fallah, M., . Rothenberrger, A.Z. Anorg. Allg. Chem. 2007, 633, 440 (d) W. Shi, M.

Shafaei-Fallah, L. Zhang, E. Matern, A. Rothenberrger, Chem. Eur. J. 2007, 13, 598

(50) Gray, I.P.,. Slawin, A.M.Z.,. Woollins,,J.D. Dalton Trans. 2005, 2188(b) Hua, G., Randall, R.A.M, Slawin, A.M.Z., Woollins, J.D., Z.Anorg.allgem.Chem., 2011, 637,1800

(51) Organic Phosphorus-Selenium Chemistry G Hua and J. D. Woollins. Chapter 1 In Selenium and Tellurium Chemistry eds J D Woollins and R Laitinen Springer Berlin 2011

(52) Hua, G., Woollins, J.D. Angew. Chem.Int Ed Engl, 2009, 48,1368

(53) Hua, G., Li, Y.,. Slawin, A.M.Z., Woollins, J.D., Org. Lett. 2006, 8, 5251 .

(54) Bethke,J.,. Karaghiosoff, K., Wessjohann, L.A.,Tetrahedron Lett. 2003, 44, 6911.

(55) Bhattacharyya, P.,Woollins,J.D. Tetrahedron Lett. 2001, 42, 5949.

(56) Li,Y., Hua,G., Slawin, A.M.Z., Woollins, J.D.Molecules, 2009, 14, 884 .

(57) Hua, Y. Li, A. M. Z. Slawin, J. D. Woollins, Dalton Trans. 2007, 1477.

(58) Bhattacharyya, P.,Slawin, A.M.Z., Woollins,J.D. J. Chem. Soc., Dalton trans. 2001, 300.

(59) Bhattacharyya, P., Slawin, A.M.Z., Woollins, J.D. Chem. Eur. J. 2002, 8, 2705.

(60) Hua, Y. Li, A. M. Z. Slawin, J. D. Woollins, Chem. Commun. 2007, 1465.

(61) Bhattacharyya, P., Slawin, A.M.Z., Woollins, J.D, Angew. Chem. Int. Ed. 2000, 39, 1973

(62) Hua,G., Henry, J.B., Li,Y., Mount, A. R., Slawin, A.M.Z., Woollins, J.D., Org. Biomol. Chem., 2010, 8 , 1655

(63) Hua, G., Li,Y., Fuller, A L., Slawin, A.M.Z., Woollins, J.D., Eur J Org Chem 2009, 1612.

(64) (a) Bhattacharyya, P., Slawin, A.M.Z., Woollins, J.D,, J. Organomet. Chem. 2001, 623, 116 (b) Hua, G., Fuller,
A L., Li,Y., Slawin, A.M.Z., Woollins, J.D.,New J. Chem., 2010, 34, 1565

(65) (a) Hua, G., Li,Y. Slawin, A.M.Z., Woollins, J.D.,, Angew. Chem. Int. Ed. 2008, 47, 2857(b) Hua, G., Li, Y., Fuller, A L., Slawin, A.M.Z., Woollins, J.D. Eur. J. Org. Chem. 2010, 2607 (c) Hua, G., Li,Y., Slawin, A.M.Z., Woollins, J.D Tetrahedron, 2008, 64, 5442

(66) Hua, G., Li,Y., Slawin, A.M.Z., Woollins, J.D.,, Polyhedron., 2011, 30, 805.

(67) Hua, G. Fuller, A.L.,. Bühl, M.,. Slawin A.M.Z. Woollins,J.D. Eur.J.Org.Chem., 2011, 3067

(68) Hua, G., Griffin, J.M., . Ashbrook, S.E., . Slawin A.M.Z., Woollins, J.D., Angew. Chem. Int. Ed. Engl., 2011, 50, 4123 . 
Please place the biographical sketch here, this will be placed on the first (Synpacts) or second page (Accounts) of the article at the galley proof stage. You may also place the photograph(s) of the authors here, alternatively you can send them by regular mail to the editorial office.

Please place the graphical abstract and short title of the article here. The short title will be used as a running header.

\section{Manuscript submission checklist}

- Statement of significance of work.

- Full mailing address, telephone, and fax numbers, and email address of the corresponding author.

- Graphical abstract.

- 5 key words.

- Paper saved as a PDF file.

- Original Word file.

- Original graphics files.

- Biographical sketches of the authors. xxx

- Photographs of the authors, if not included the hardcopies should be sent by regular mail to the Editorial Office after the manuscript is accepted.

Send all materials on this list to the Editor-in-Chief. Keep the original Word and graphics files for revisions and for final submission after acceptance. 